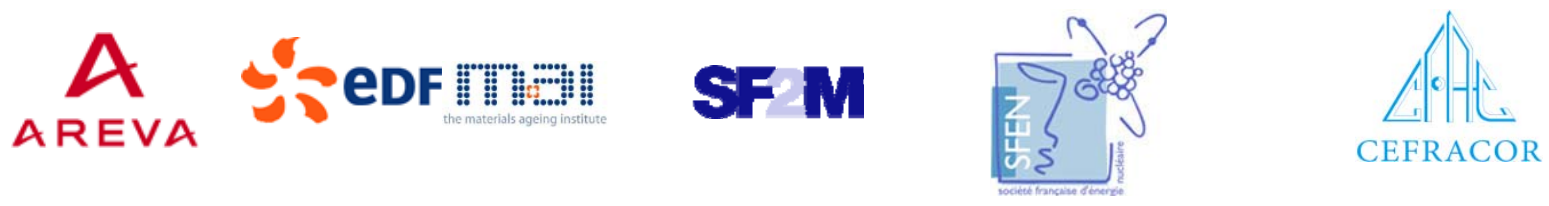

\section{MIN口S}

Centre of Excellence for Nuclear Materials

\section{Workshop}

Materials Innovation for Nuclear Optimized Systems
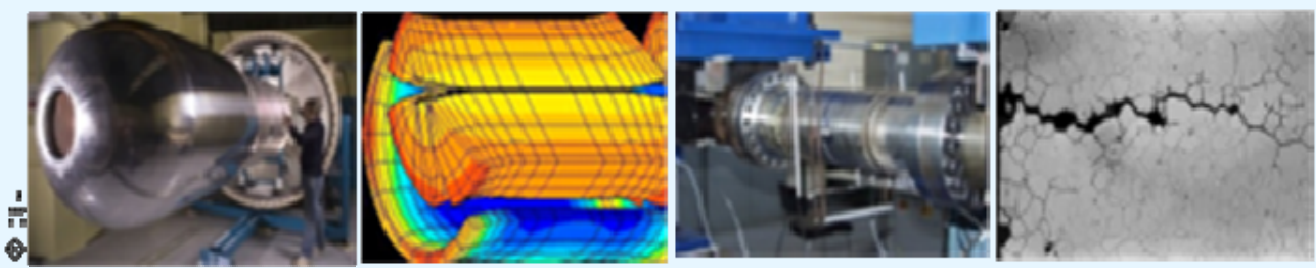

December 5-7, 2012, CEA - INSTN Saclay, France

\section{Philippe MAGAUD et al. \\ CEA (France)}

Plasma Facing Components: Challenges for Nuclear Materials

Workshop organized by:

Christophe GALLÉ, CEA/MINOS, Saclay - christophe.galle@cea.fr Constantin MEIS, CEA/INSTN, Saclay - constantin.meis@cea.fr 
MINDS

Workshop

\title{
Plasma Facing Components: Challenges For Nuclear Materials
}

\author{
Philippe MAGAUD ${ }^{1}$, Jérôme BUCALOSSI ${ }^{1}$, Antonella LI PUMA ${ }^{2}$, Marc MISSIRLIAN $^{1}$, \\ Marianne $\mathrm{RICHOU}^{1}$ \\ ${ }^{1}$ CEA-DSM-IRFM, Service Intégration Plasma-Paroi, SIPP (Cadarache, France) \\ ${ }^{2}$ CEA-DEN-DM2S, Service d'Etudes des Réacteurs et de Mathématiques Appliqués, SERMA (Saclay, France)
}

In current fusion devices, the components located in front of plasma, the so-called plasma facing components (PFCs), sustain severe constraints such as high thermal flux (several $\mathrm{MW} / \mathrm{m}^{2}$ ), erosion, flux of particles. The management of this first material interface is critical from a plasma performance point of view. ITER, as nuclear facility, is initiating a new era for fusion, which will be reinforced for a future fusion power plant which will add specific requirements (sufficient lifetime, a cooling system to produce energy, use of low activation material) while increasing nuclear constraints.

The talk will recall in a first part the main requirements of an actively plasma facing components and the main results obtained with low-Z carbon based PFCs (mainly CFC). Experimental feedback from these challenging components is an essential step for the success of the next generation of components, in particular in term of manufacturing or handling intense heat loads.

Nuclear safety requirements mainly drive the need of new materials for the nuclear phase of ITER. The tritium retention in carbon based PFCs and the strong erosion are expected to be too high in the Deuterium-Tritium phase with CFC targets, justifying the use of high-Z materials. The evolution toward high- $Z$ materials, with tungsten the most promising, becomes a major challenge for fusion research. Large scale experiences with $W$ have only been obtained recently with the operation of ASDEX-upgrade and JET tokamaks but with non-actively cooled PFCs. ASDEX-upgraded is equipped with W coated carbon PFCs while JET includes W coated carbon PFC and inertially cooled solid W, using in all cases a technology not relevant for ITER. Extensive R\&D programmes have been performed in Europe to develop reliable actively PFCs for ITER [1-5]. The state of the art will be presented including specific devices needed to fully qualify, at laboratory scale, designs foreseen for ITER. In order to reduce the risks and anticipate any difficulties ITER may face in terms of manufacturing or operation, it is proposed to update Tore Supra with a full W first wall and divertor, benefitting from the unique long pulse capabilities of the Tore Supra platform, the high installed power and the long history of operation with actively cooled high heat flux components [6]. The main goals of the 'WEST' project (W - for tungsten -Environment in Steady-state Tokamak, figure 1) will be presented.

The talk will also address acknowledged gaps in PFCs developments for DEMO, which require extensive studies in different topics, from plasma-surface interaction to engineering including material sciences. Further challenges address simultaneously the higher power density, high-temperature wall, bulk (neutron) and surface (charged particle) accumulated damage. The high neutron fluence expected in a fusion reactor (more than10 dpa/year) will affect erosion and tritium retention properties of materials. Near-surface material properties will be for instance altered by the neutron damage. Such synergistic effects are expected to be important in the DEMO environment and are difficult to be addressed experimentally. A more robust coupling of materials development, including fundamentally studies, with advanced design is required. If tungsten is the most promising material for the plasma-facing, tungsten also offers less favorable properties (recrystallization, which influences the mechanical properties, embrittlement as a result of neutron-induced damages, Heinduced sputtering...) that have to be resolved. Only a global approach, including fundamental science, material development, joining/welding techniques, design innovation and a close link with plasma physics is able to reach the necessary level of credibility for operating such components in a fusion environment in an economically reasonable way. 


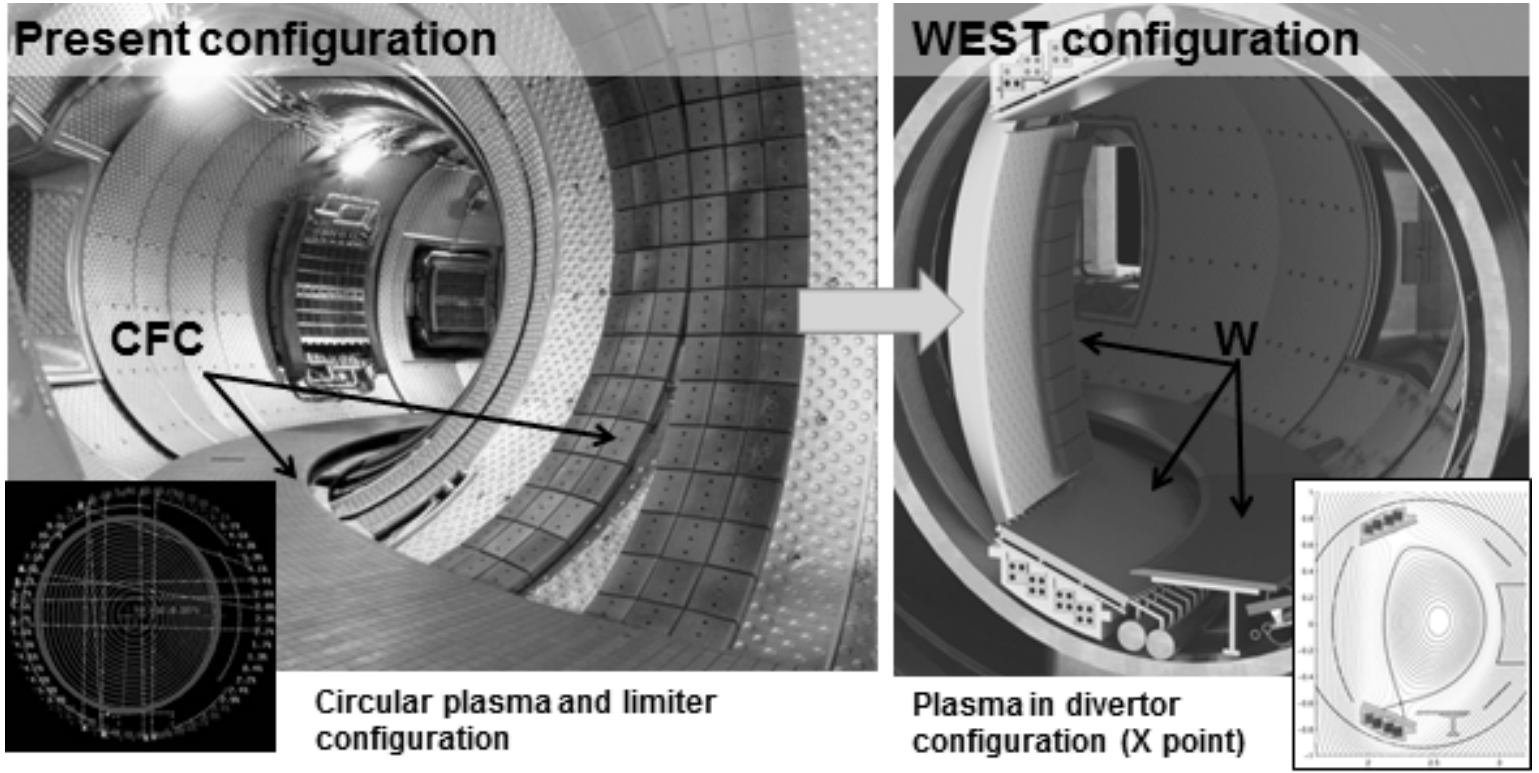

Fig. 1: The 'WEST' project is a major update of Tore Supra to address the issues related to tokamak operation with W actively cooled ITER relevant PFCs. Internal components, presently in CFC will be updated to W components (ITER technology) and the magnetic plasma configuration (presently circular) will be changed to X-point configuration by installing a set of poloidal coils inside the lower and upper parts of the vacuum vessel.

\section{References}

[1] - M. Missirlian, M. Richou, B. Riccardi, P. Gavila, T. Loarer and S. Constans, The Heat removal capability of actively cooled plasma-facing components for ITER divertor. Physica Scripta, T145 (2011).

[2] - M. Richou, M. Missirlian, B. Riccardi,, P. Gavila, C. Desgranges, N. Vignal, V. Cantone and S. Constans, Fatigue lifetime of repaired high heat flux components for ITER divertor. Fusion Engineering and Design 86 (2011) pp. 1771-1775.

[3] - M. Missirlian, F. Escourbiac, A. Schmidt, B. Riccardi and I. Bobin-Vastra, Examination of high heat flux components for the ITER divertor after thermal fatigue testing. Journal of Nuclear Materials 417 (2011) pp. 597-601.

[4] - D. Serret, M. Richou, M. Missirlian and T. Loarer, Mechanical characterization of W-armoured plasma-facing components after thermal fatigue. Physica Scripta, T145 (2011).

[5] - A. Durocher et al., Infrared thermography inspection of the ITER vertical target qualification prototypes manufactured by European industry using SATIR. Fusion Engineering and Design 84 (2009) 314-318.

[6] - J. Bucalossi et al., Feasibility study of an actively cooled tungsten divertor in Tore Supra for ITER technology testing. Fusion Engineering and Design, Volume 86, Issues 6-8, October 2011, Pages 684-688. 
MINOS workshop (Saclay, 5-7 december 2012)

DE LA RECHERCHE À L'INDUSTRIE

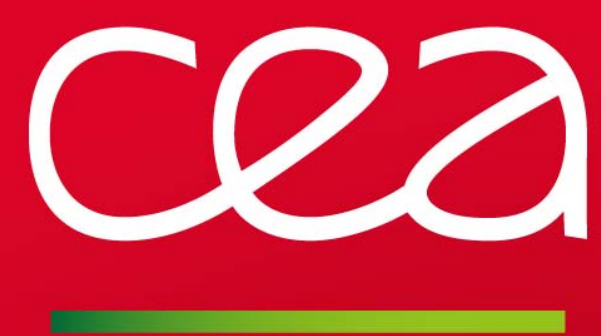

infin

www.cea.fr
Plasma facing components: challenges for nuclear materials

Ph. Magaud ${ }^{1}$, J. Bucalossi ${ }^{1}$, A. Li Puma², M. Missirlian ${ }^{1}$, M. Richou ${ }^{1}$

${ }^{1}$ CEA/IRFM (CADARACHE, FRANCE),

2 CEA/DM2S (SACLAY, FRANCE)

Institut de Recherche sur la Fusion par confinement Magnétique (IRFM) CEA Cadarache

13108 St Paul Lez Durance 


\title{
CEA CONTENTS
}

\author{
Fusion basics
}

From present Plasma Facing Components (PFC)...

.. to PFC for ITER

Toward a fusion reactor 


\section{CeA ENERGY FROM NUCLEUS}

$\mathbf{B}(\mathbf{A}, \mathbf{Z}) / \mathbf{A} \quad$ Stable elements

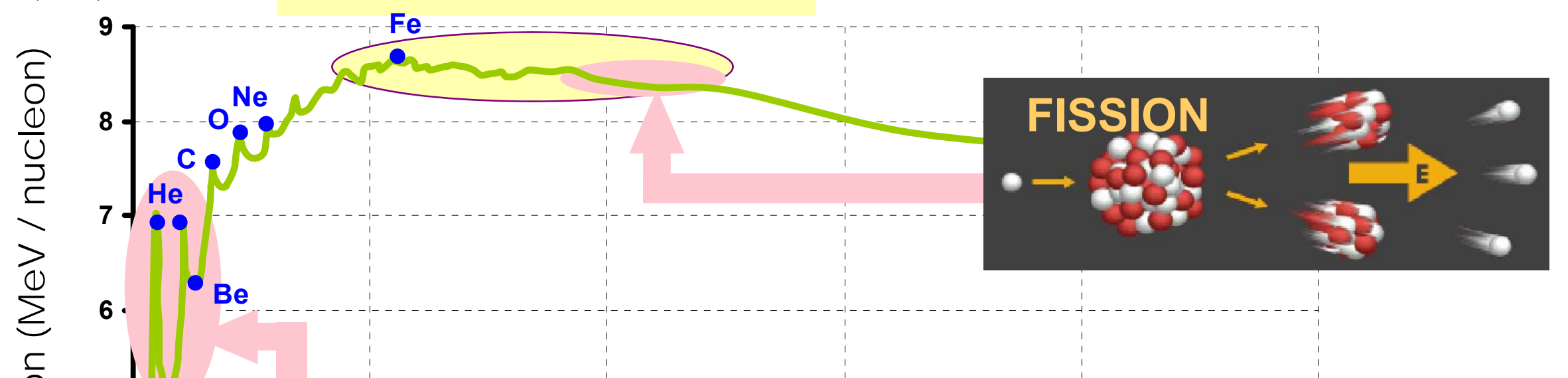

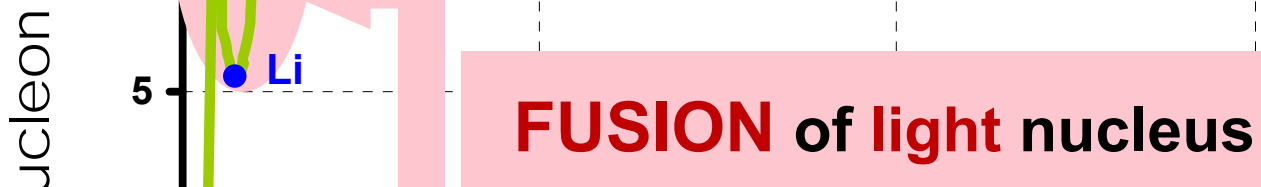

>

\section{Ex : D $+\mathrm{T} \rightarrow \mathrm{He}$}

$(3.6 \mathrm{MeV})+(14 \mathrm{MeV})$
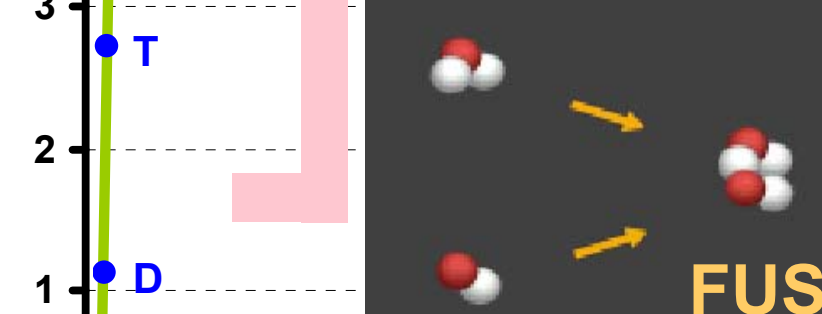

.

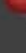

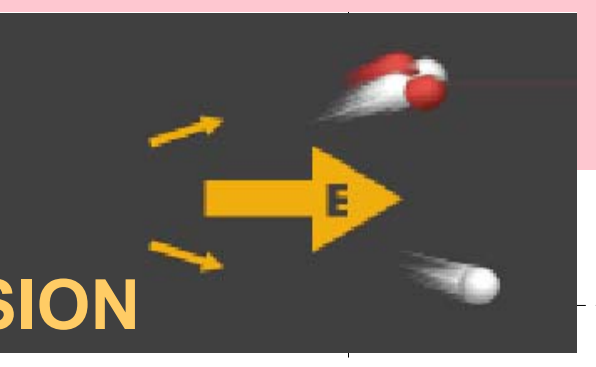

The fusion of charged partic les needs very high $\mathbf{T}^{\circ}$ (100 million degrees)

At those T, matter is a plasma
$\mathrm{Nb}$ of nucleons (A) 


\section{CEA FUSION ON EARTH}

\section{On SUN \& STARS}

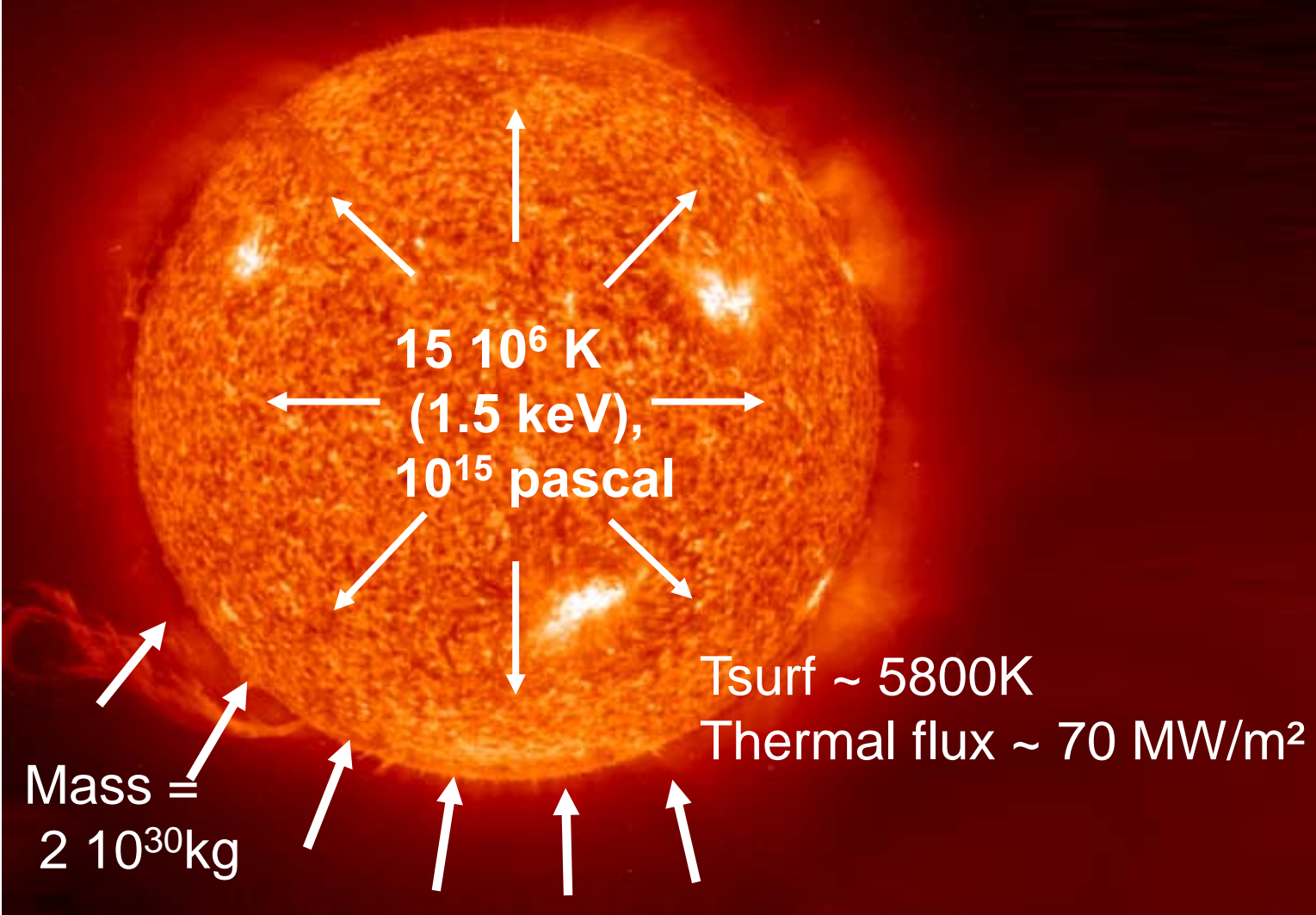

Confinement $=$ GRAVITY

high $\mathrm{T}^{\circ} \&$ pressure for long time 


\section{CEA FUSION ON EARTH}

\section{On EARTH}

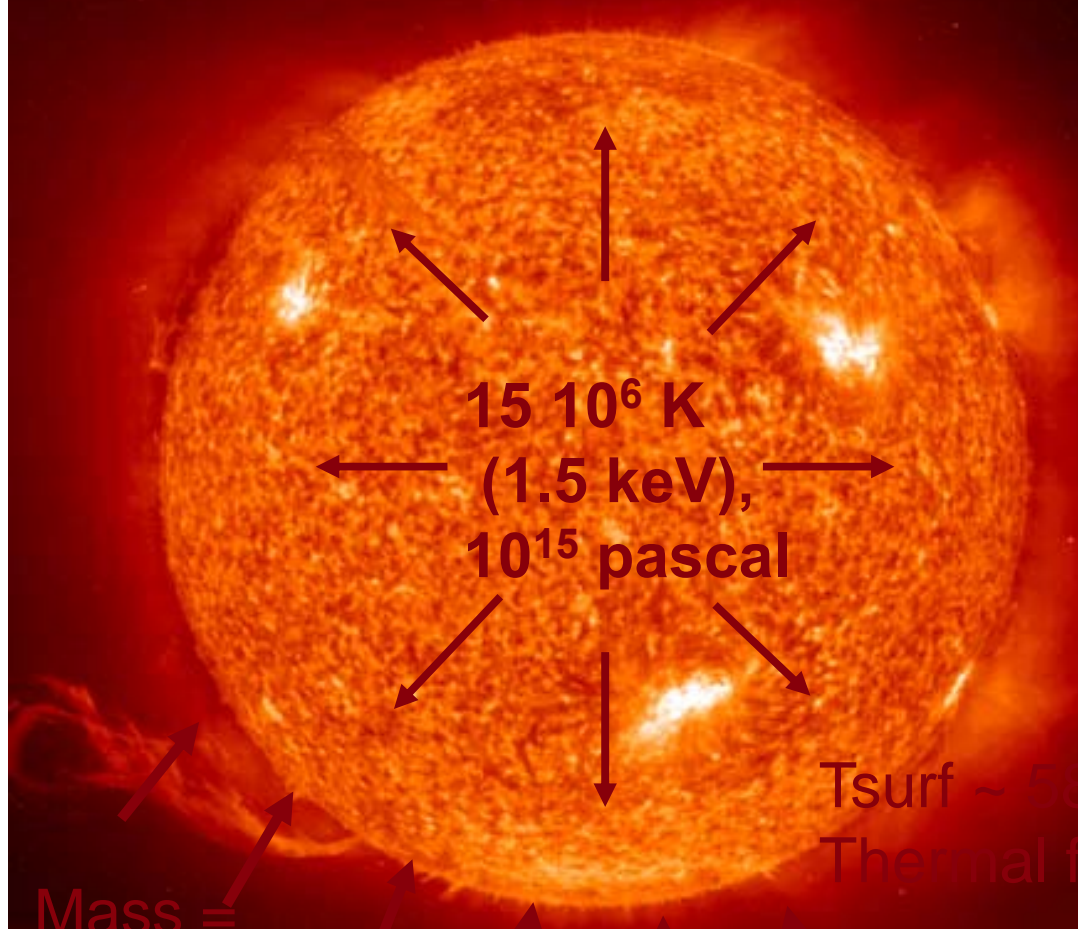

1 - Confine the plasma into a magnetic botte $\rightarrow$ MAGNEIC fusion

- Characteristic time (time for plasma to exhaust power=confinement time ): seconde

- Plasma volume $\sim 1000 \mathrm{~m}^{3}$ with only few $\mathrm{g}$ of fuel (low density)

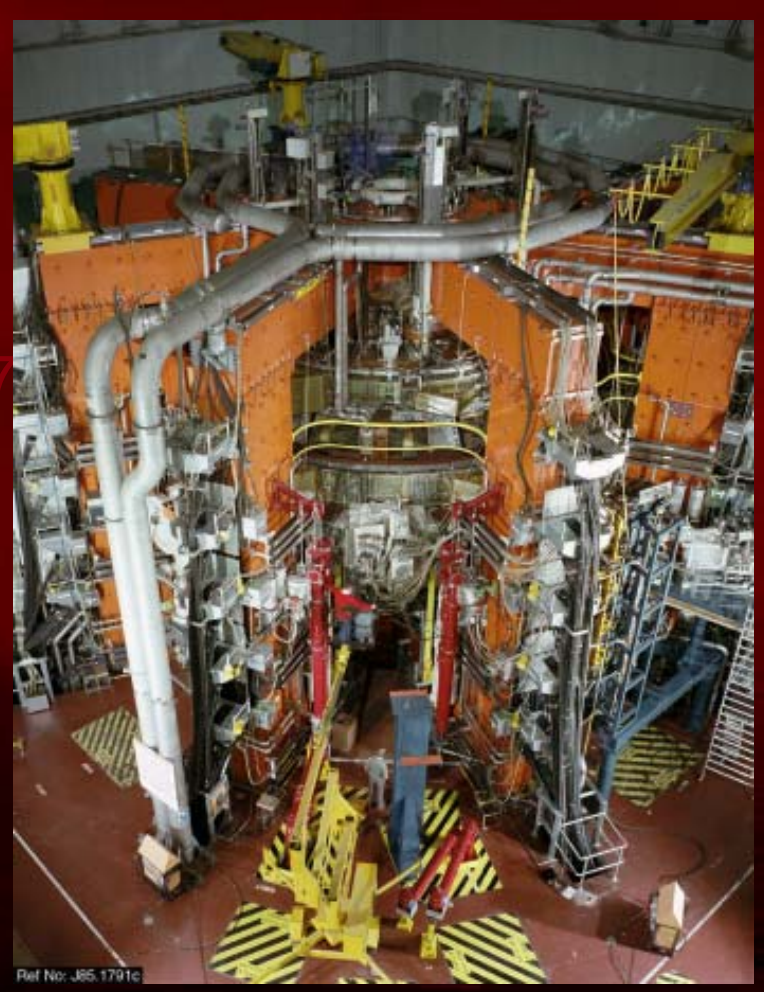

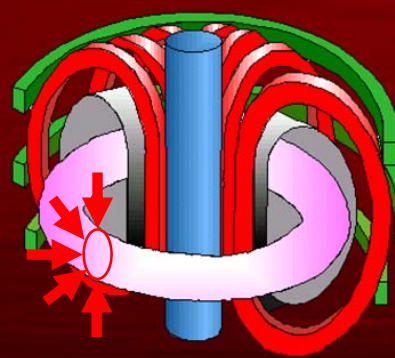

JET Tokamak (Joint European Torus) 


\section{CEA FUSION ON EARTH}

\section{On EARTH}

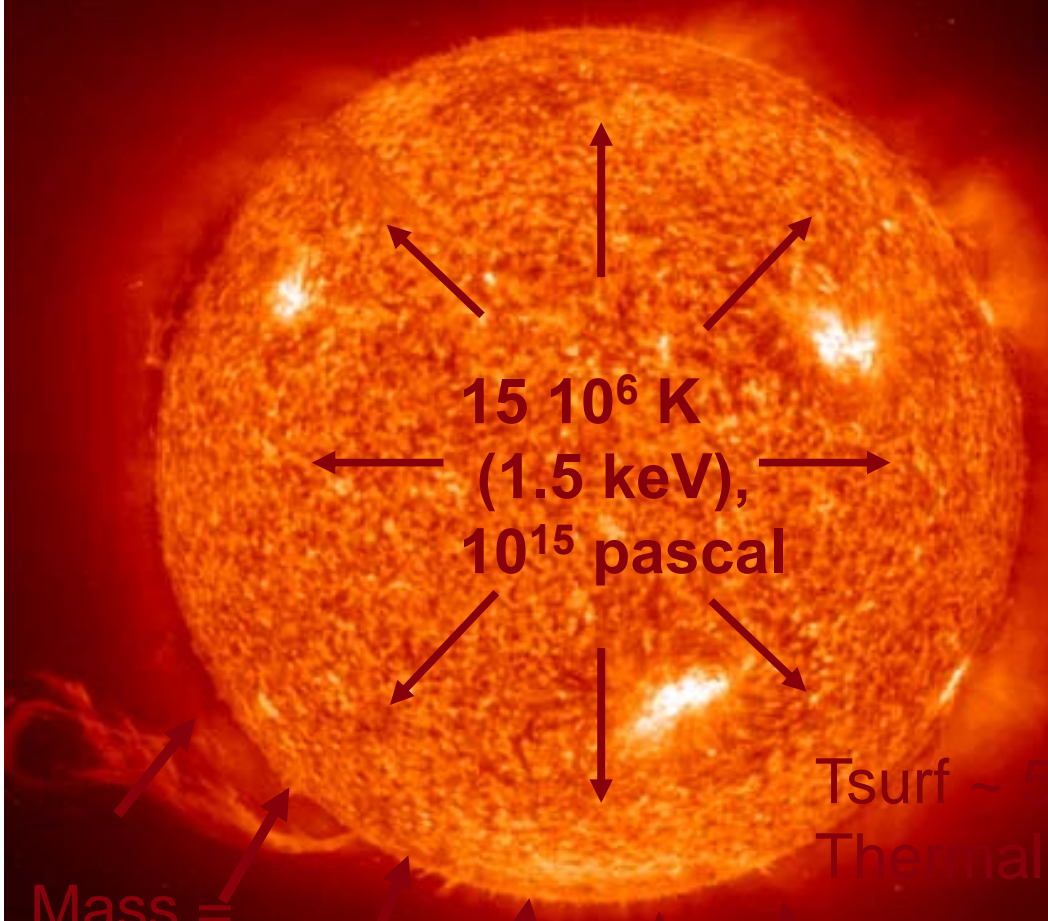
section
1 - Confine the plasma into a magnetic bottle $\rightarrow$ MAGNEIC fusion

2 - Use fusion reaction with the highest cross

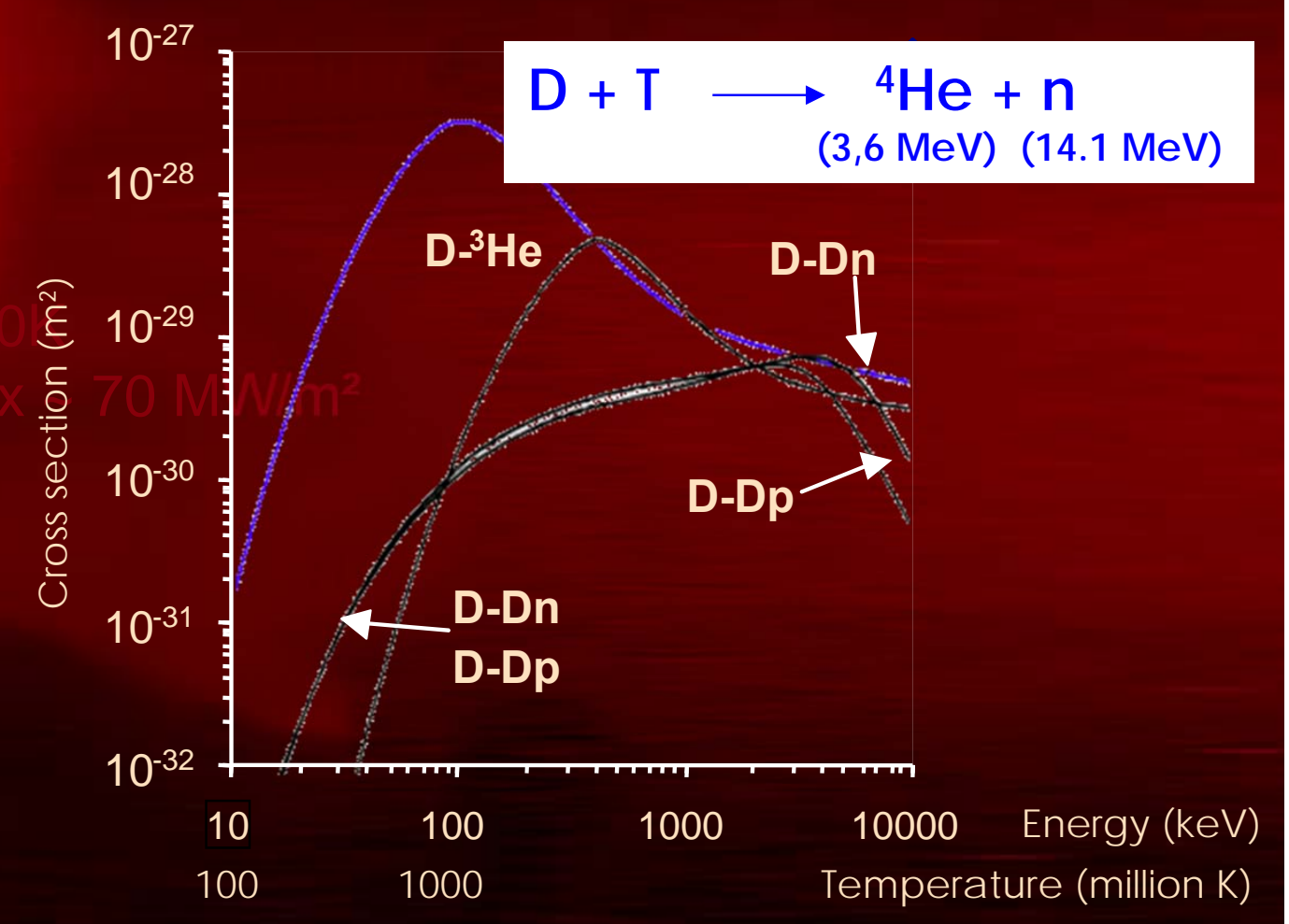




\section{Cea PLASMA FACING COMPONENTS}

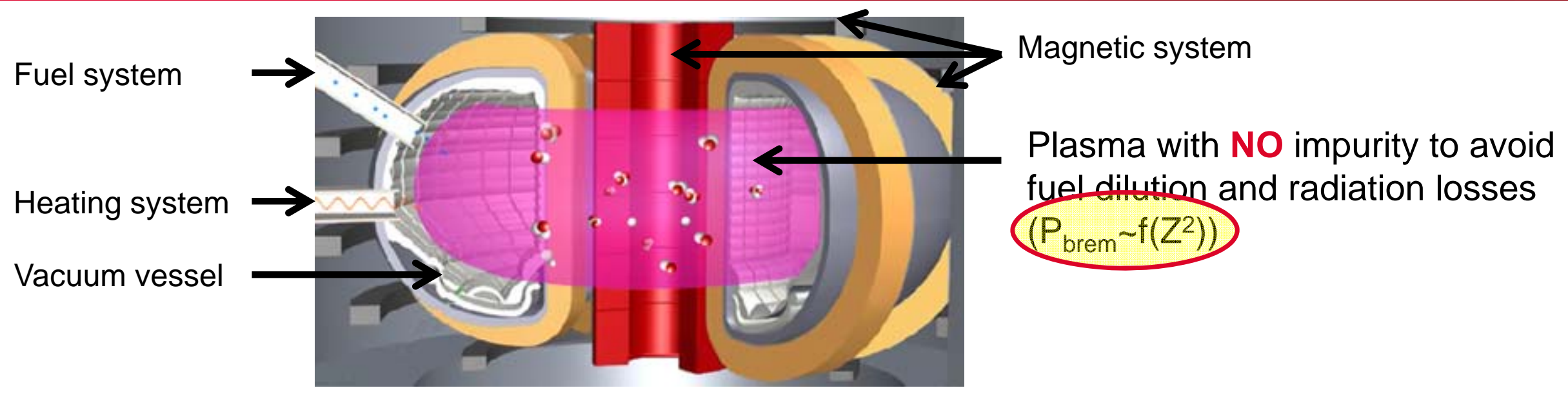

Plasma does not like materials with high atomic number!!
The fatal fraction of an impurity is the concentration at which the radiated power (impurity line radiation and Bremmstrahlung radiation) exceeds the alpha heating power

$$
\begin{aligned}
& C \sim 10^{-1} \\
& W \sim 10^{-4}
\end{aligned}
$$

$\rightarrow$ Close links between the surface material and the plasma core 


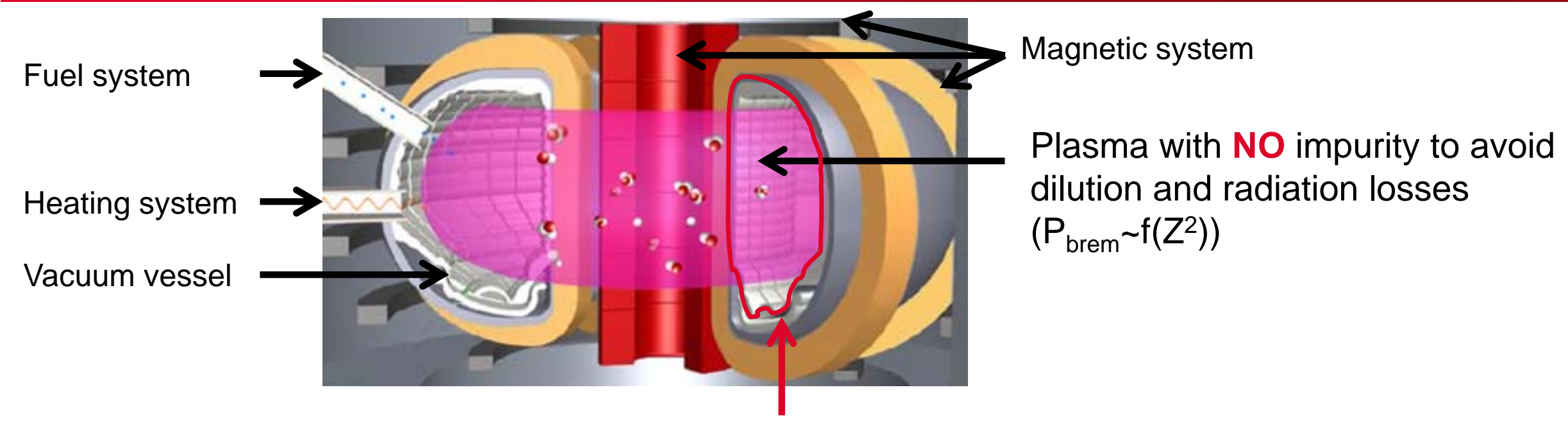

Components in interaction with the plasma $=$ Plasma Facing Components (PFC)

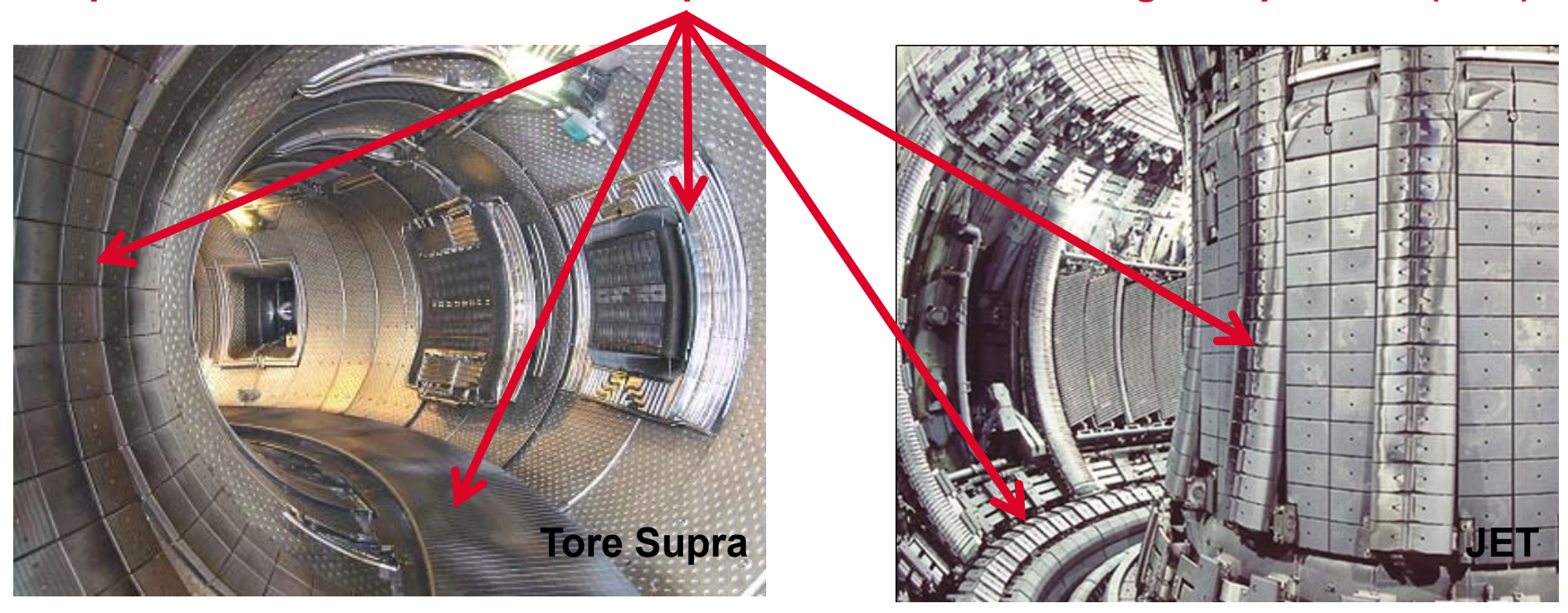




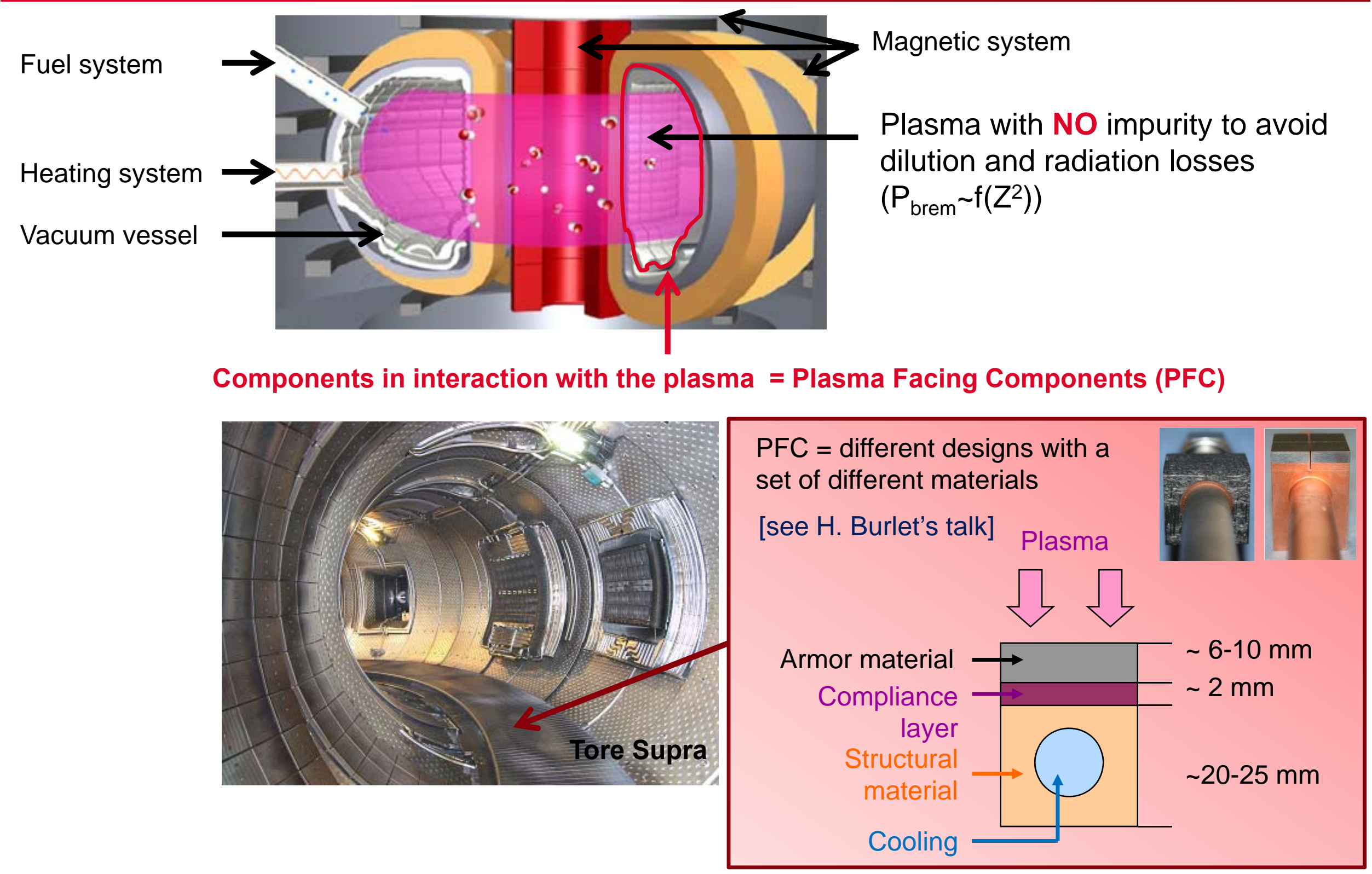


Confinement is never perfect $\rightarrow$ management of the deconfined particles leaving the plasma core on a specific component: divertor $\rightarrow$ heat and particles removal

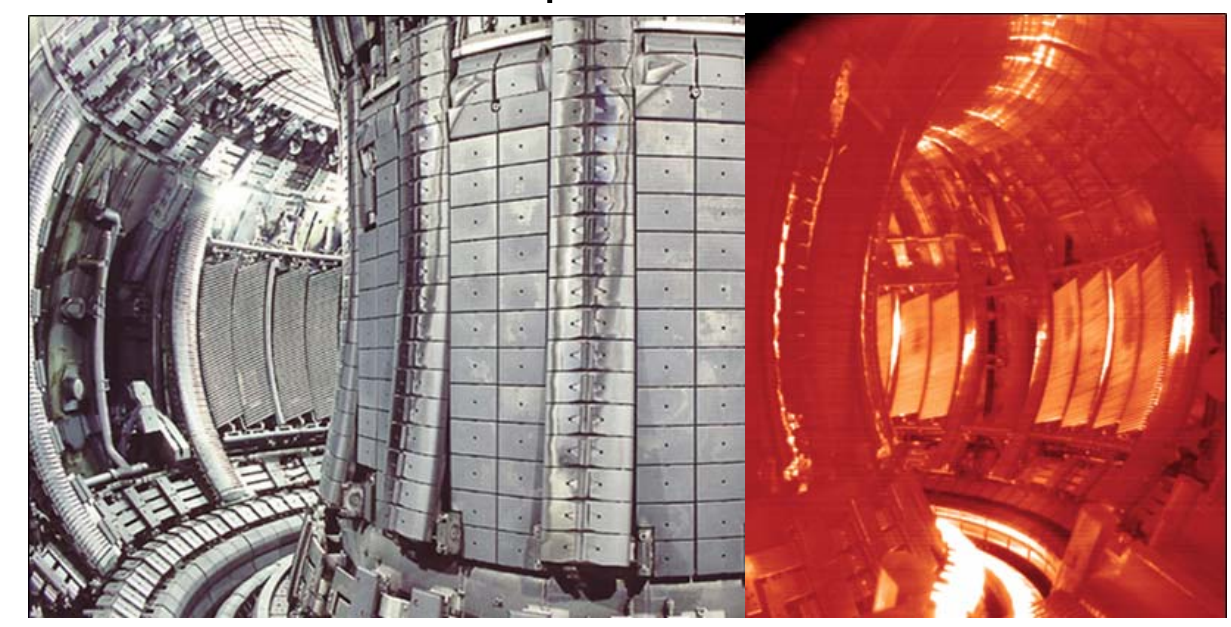

Divertor in JET : without and with plasma

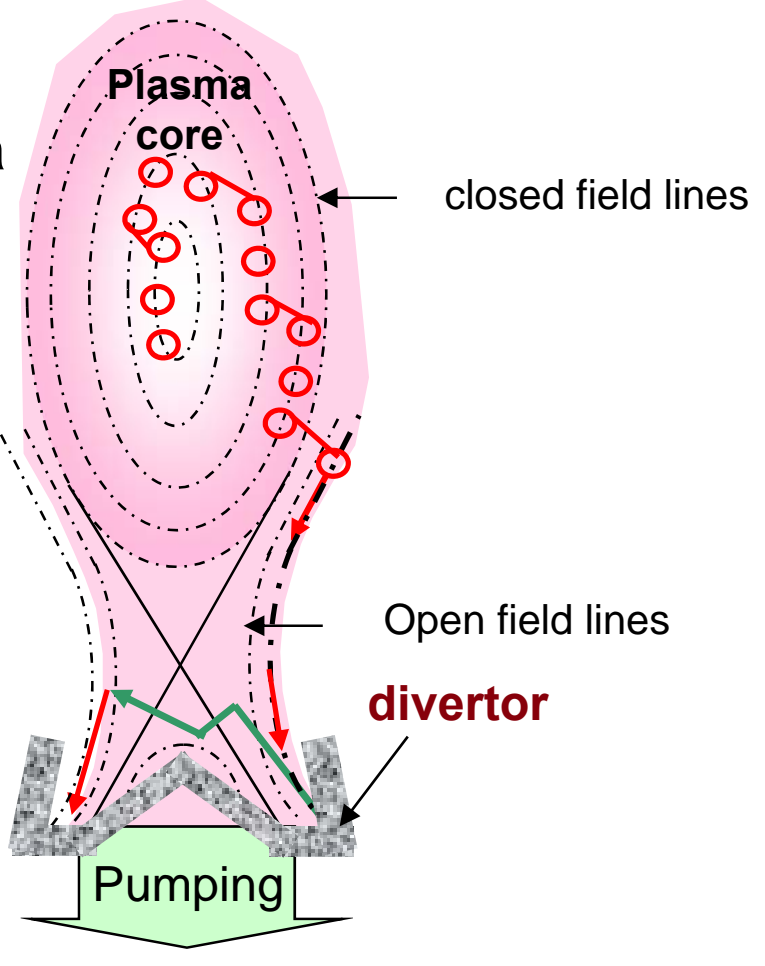

Advantage : Concentrate power and particle exhaust in one location (far from the plasma core)

Disadvantage : Concentrate power and particle exhaust in one location 
Confinement is never perfect $\rightarrow$ management of the deconfined particles leaving the plasma core on a specific component: divertor $\rightarrow$ heat and particles removal

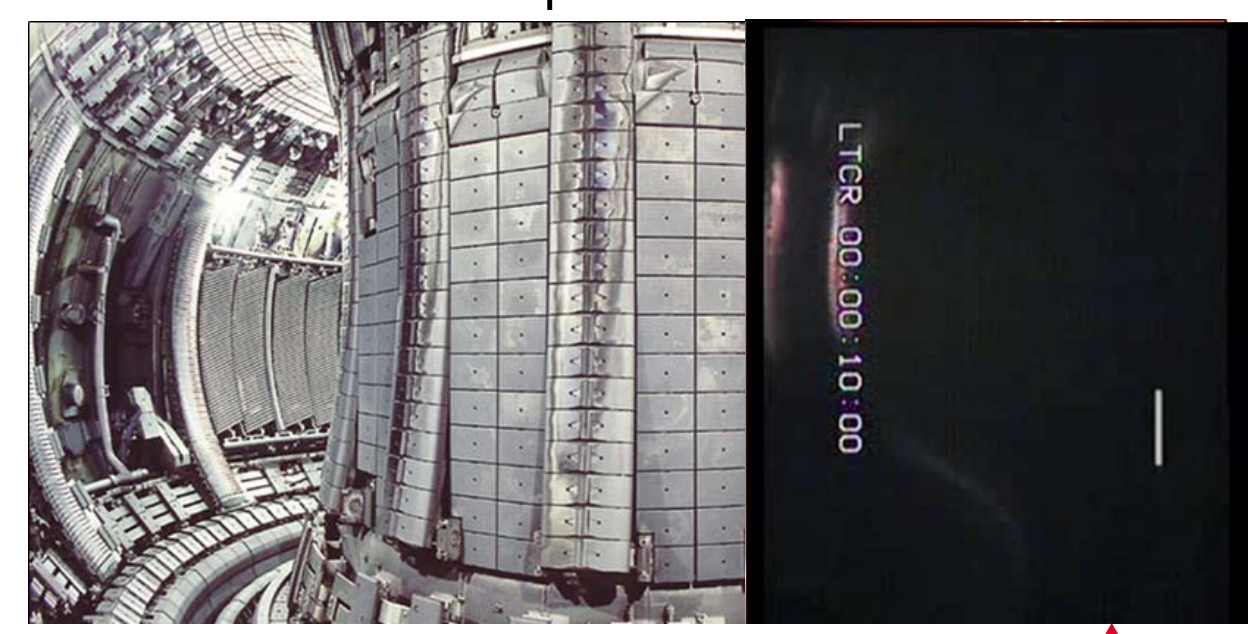

Divertor in JET : without and with plasma

Typical heat flux value:

- steady state $\rightarrow 10 \mathrm{MW} / \mathrm{m}^{2}$

- transient $(<\mathrm{ms}) \rightarrow 1-10 \mathrm{GW} / \mathrm{m}^{2} \quad$ (ELMs, misalignment of components...)

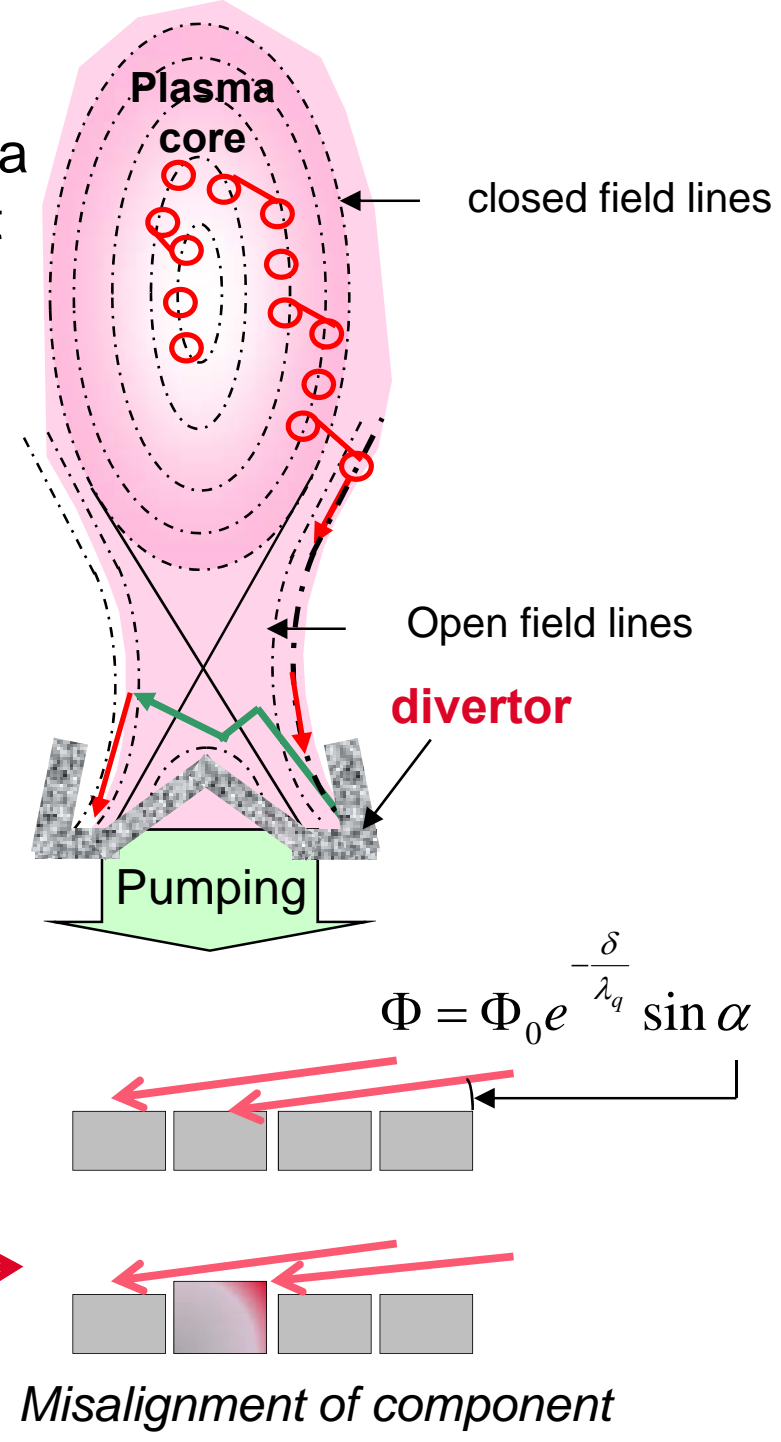


High heat flux

Erosion in the main plasma interaction area

- Production of dusts, deposits in deposition / codeposition area
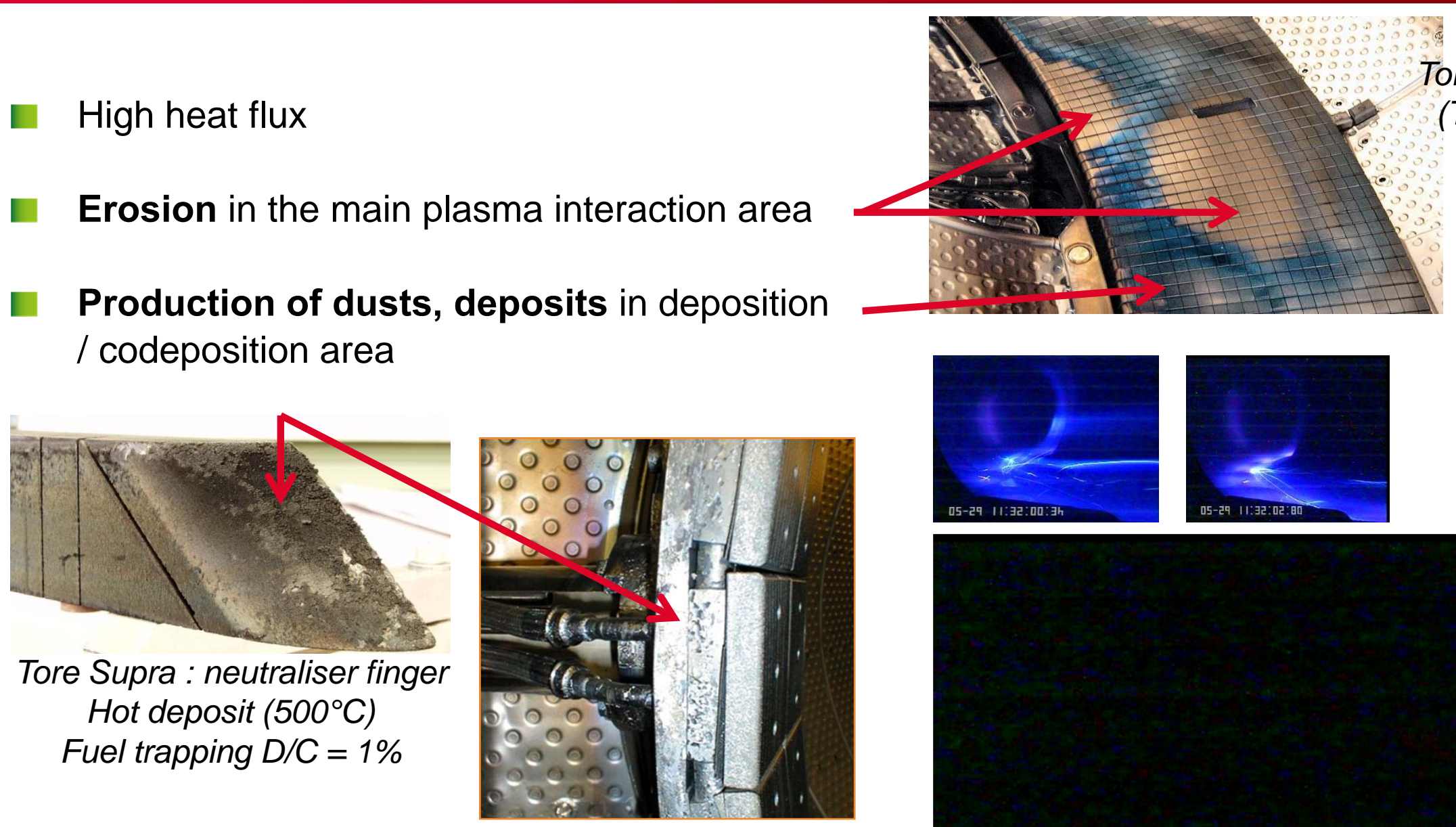

당 Toroidal Limiter (Tore Supra)

Tore Supra : outer limiter Cold deposit $\left(120^{\circ} \mathrm{C}\right) \mathrm{D} / \mathrm{C}=10 \%$

Dusts/deposits/layers have operational consequences $\rightarrow$ Emission of deposits during the plasma startup $\rightarrow$ to fast plasma termination
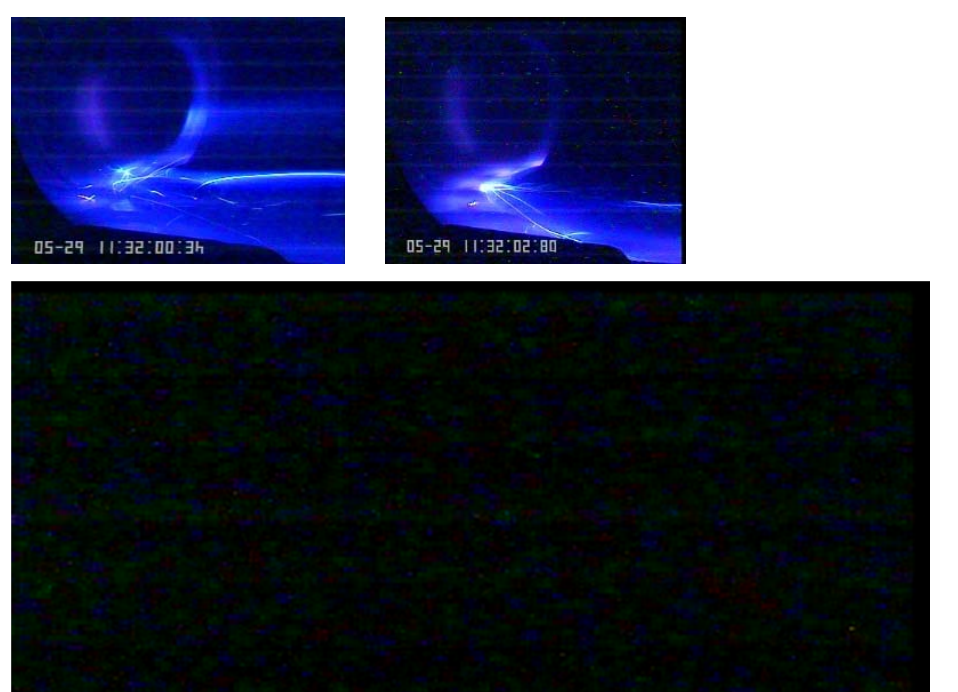


\section{CeA PRESENT TECHNOLOGIES}

tritium: $~ 100 \mathrm{~kg} / \mathrm{y}$ neutrons: 5-20 dpa/y

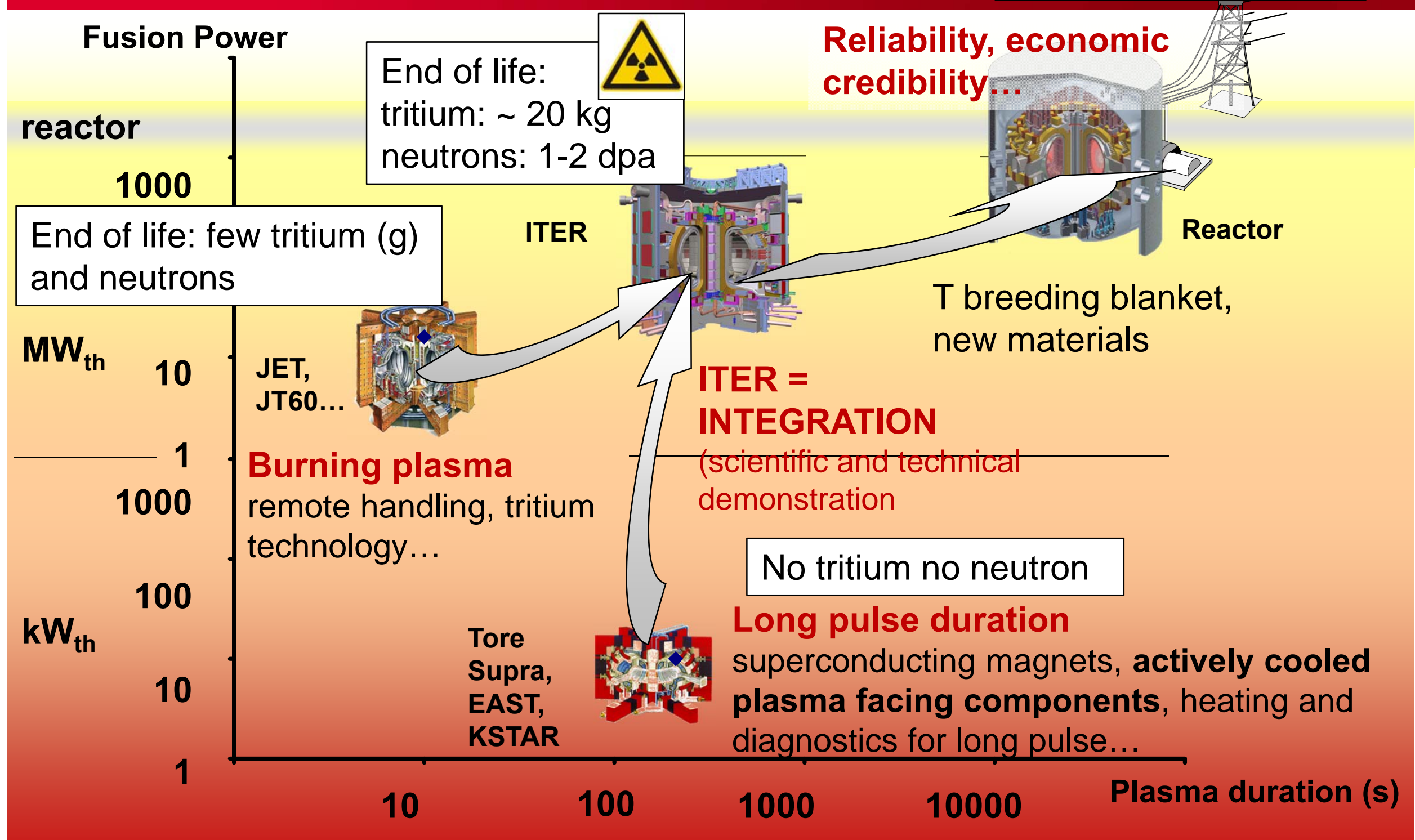


Fusion basics

From present Plasma Facing Components (PFC)...

口 ... to PFC for ITER

- Toward DEMO 


\section{Fusion basics}

For fusion guys, current world is not a nuclear world $(;)$
From present Plasma Facing Components (PFC)...

I... to PFC for ITER

- Toward DEMO 
- CFC has a good plasma compatibility (low atomic number),

- a good thermal conductivity : 50-300 W/m.K,

- and no melting, highest sublimation point : $3900 \mathrm{~K}$

$\rightarrow \mathrm{C}$ "forgives" occasional overheating

Due to low plasma fluence, drawbacks (erosion) are not an issue for present devices

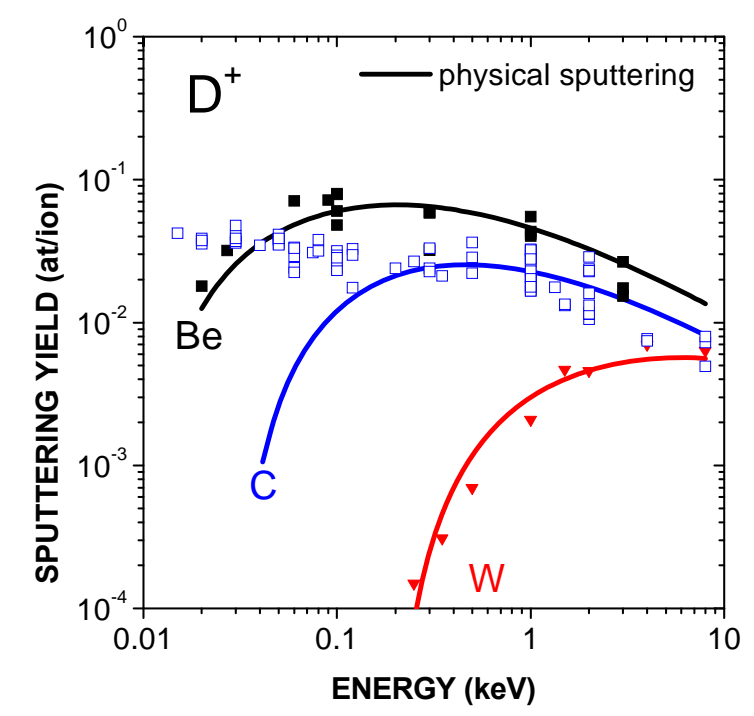

$$
\begin{aligned}
& \sim 2-3 \text { eV }<T_{\text {plasma edge }}<100 \text { eV } \rightarrow \\
& 15 \mathrm{eV}<\mathrm{E}_{\text {ions }}<500 \text { eV }
\end{aligned}
$$

Threshold for D

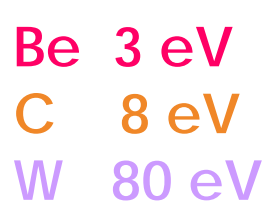

- Copper as structural material due to its high thermal conductivity 


\section{CeA PRESENT ACTIVELY COOLED TECHNOLGY}

A world of CFC and Copper (ex Tore Supra technology)

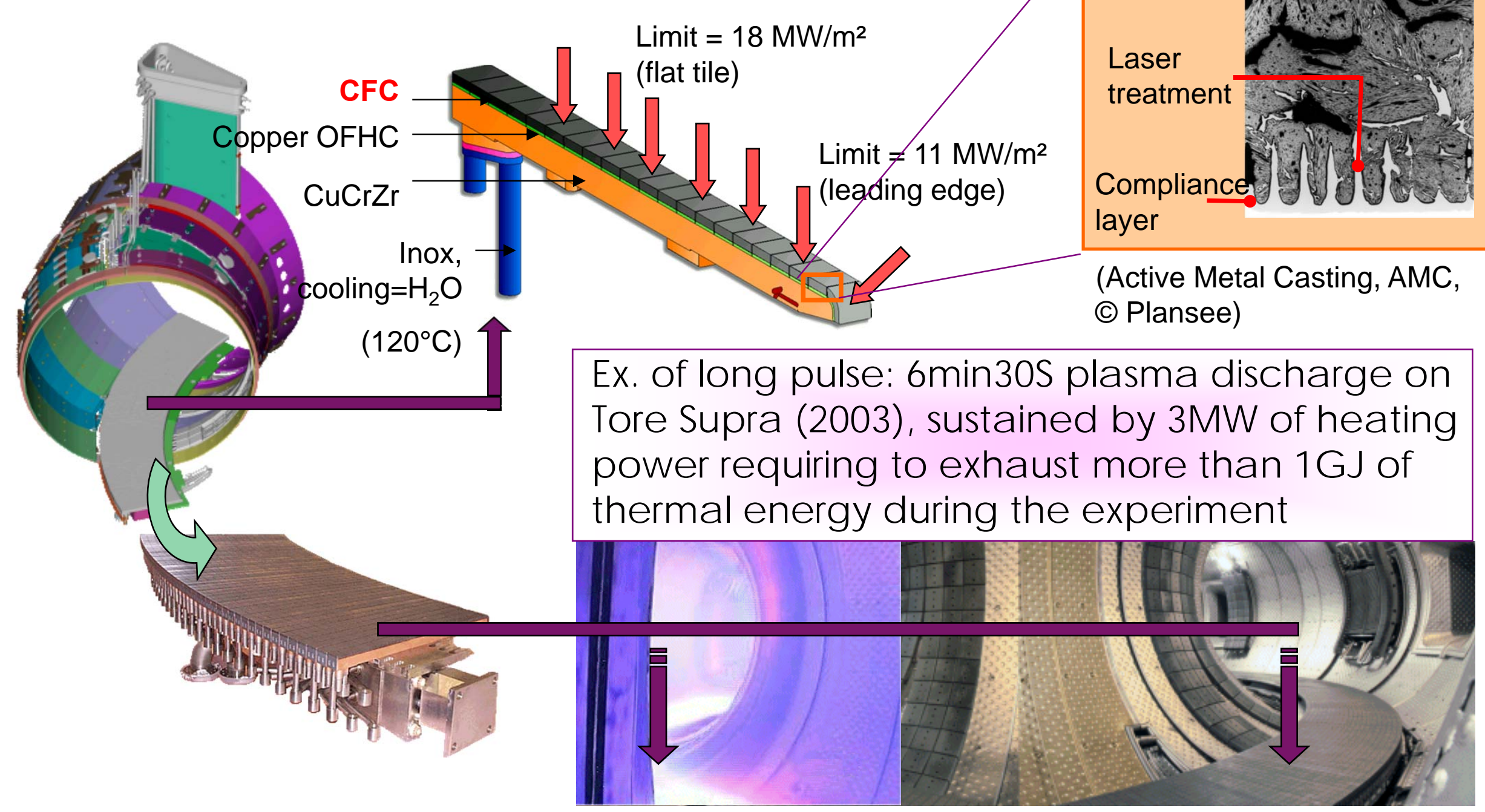

CEA/IRFM | MINOS workshop 5-7 december 2012 | PAGE 17 


\section{MAIN FEEDBACKS}

Joining is a weak link

From lab-scale to Industry: never a quiet workflow

- Carbon retains large amounts of $H(D, T) \rightarrow$ the integrated amount of deuterium recovered at the end of a plasma discharge is generally lower than the integrated injected amount

DITS project (Tore Supra, 2007-2010)

- 5h of plasma

- dismantling of part of Tore Supra components
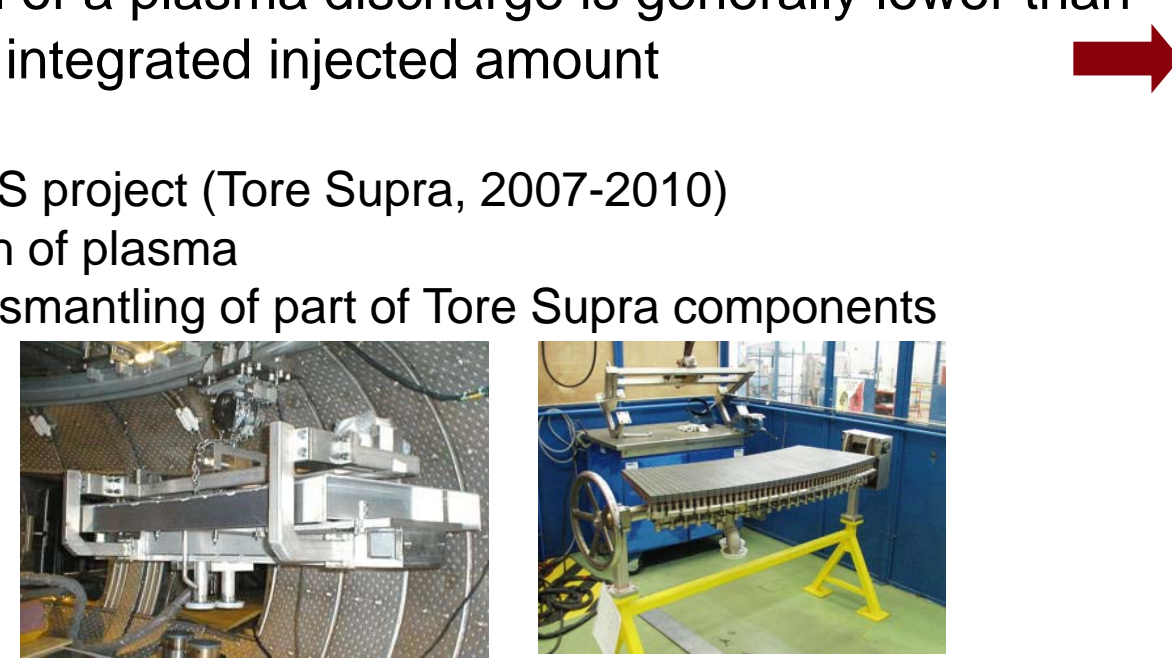

- Post mortem analysis (retention by co-deposition due to erosion dominates)

In carbon $\rightarrow$ AUG-JET (3-4\%), JT-60U 8\%, TEXTOR \& TS $\sim 10-15 \%$

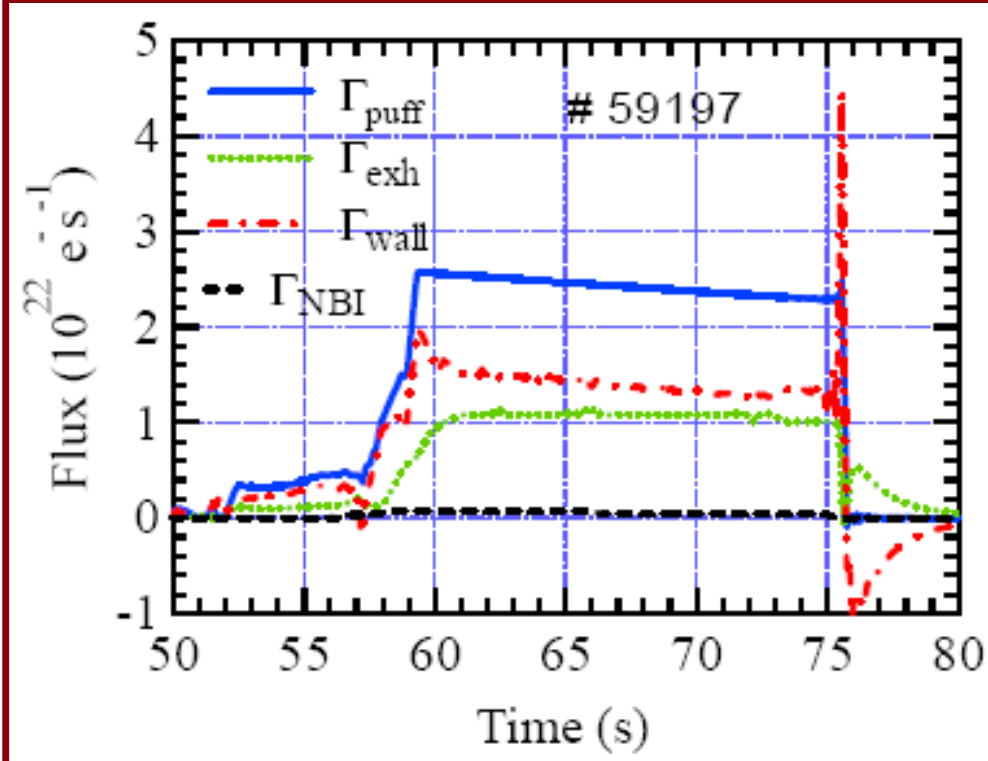

Time evolution during a plasma discharge of the injected (blue) and exhausted (green) deuterium rate. The difference between the two is the instantaneous retention rate (red). 
Fusion basics

From present Plasma Facing Components (PFC)...

a ... to PFC for ITER $\triangle$ Toward DEMO 


\section{Cea ENTERING INTO THE NUCLEAR WORLD}

- Tritium inventory is limited by Safety Authorities

ITER: $700 \mathrm{~g}$ inside the vacuum vessel

A full $C$ wall reaches tritium limit (700g) in less than 30-40 ITER nominal plasma discharges

A full $W$ wall reduces tritium problem, but n-effects need to be considered (R\&D on-going, modelling...)

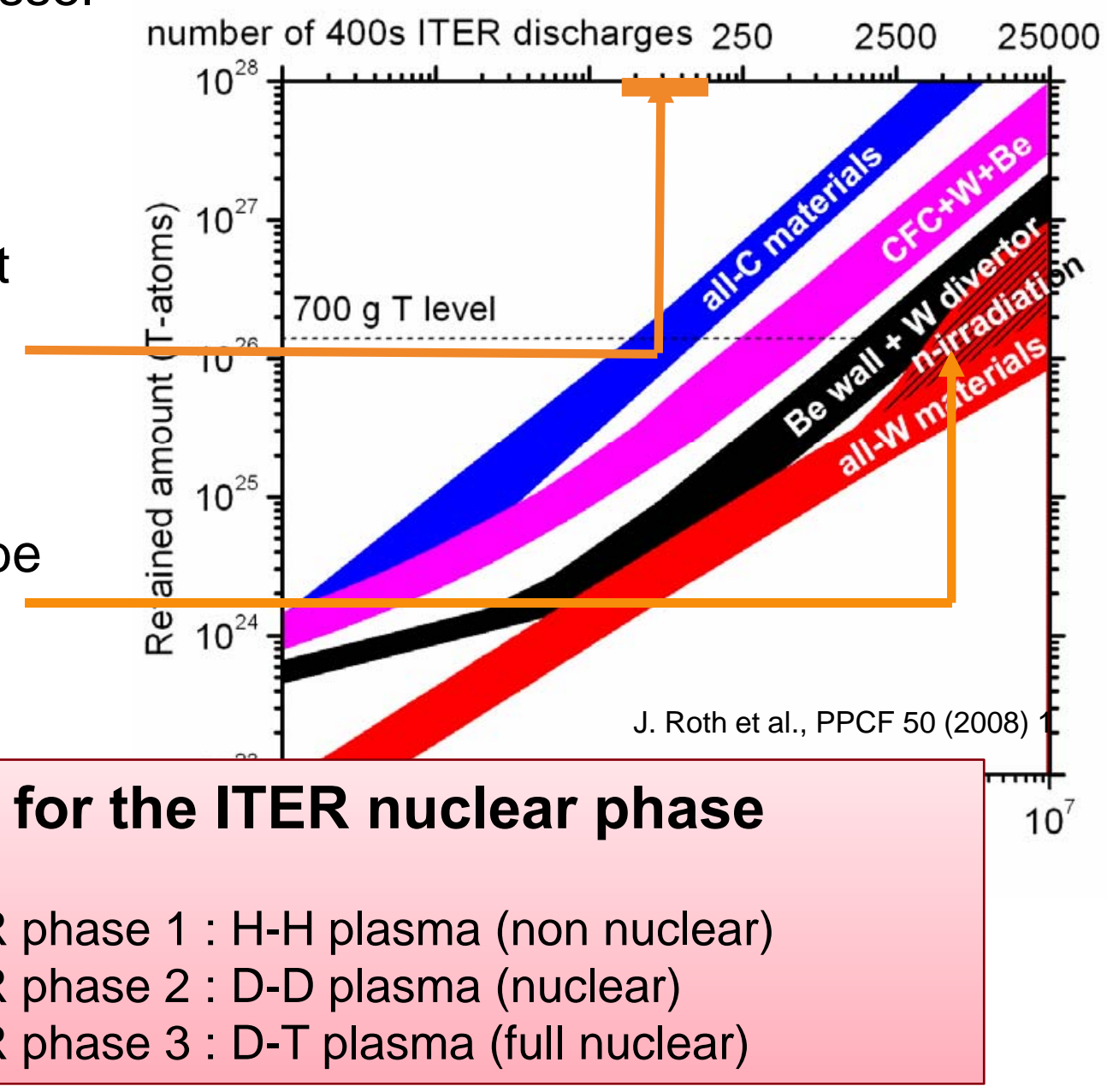

\section{CFC is not relevant for the ITER nuclear phase}

reminder:

ITER phase $1: \mathrm{H}-\mathrm{H}$ plasma (non nuclear)

ITER phase 2 : D-D plasma (nuclear)

ITER phase 3 : D-T plasma (full nuclear) 


\section{CeA ITER PFC}

A reference design for optimizing plasma performance... and cost

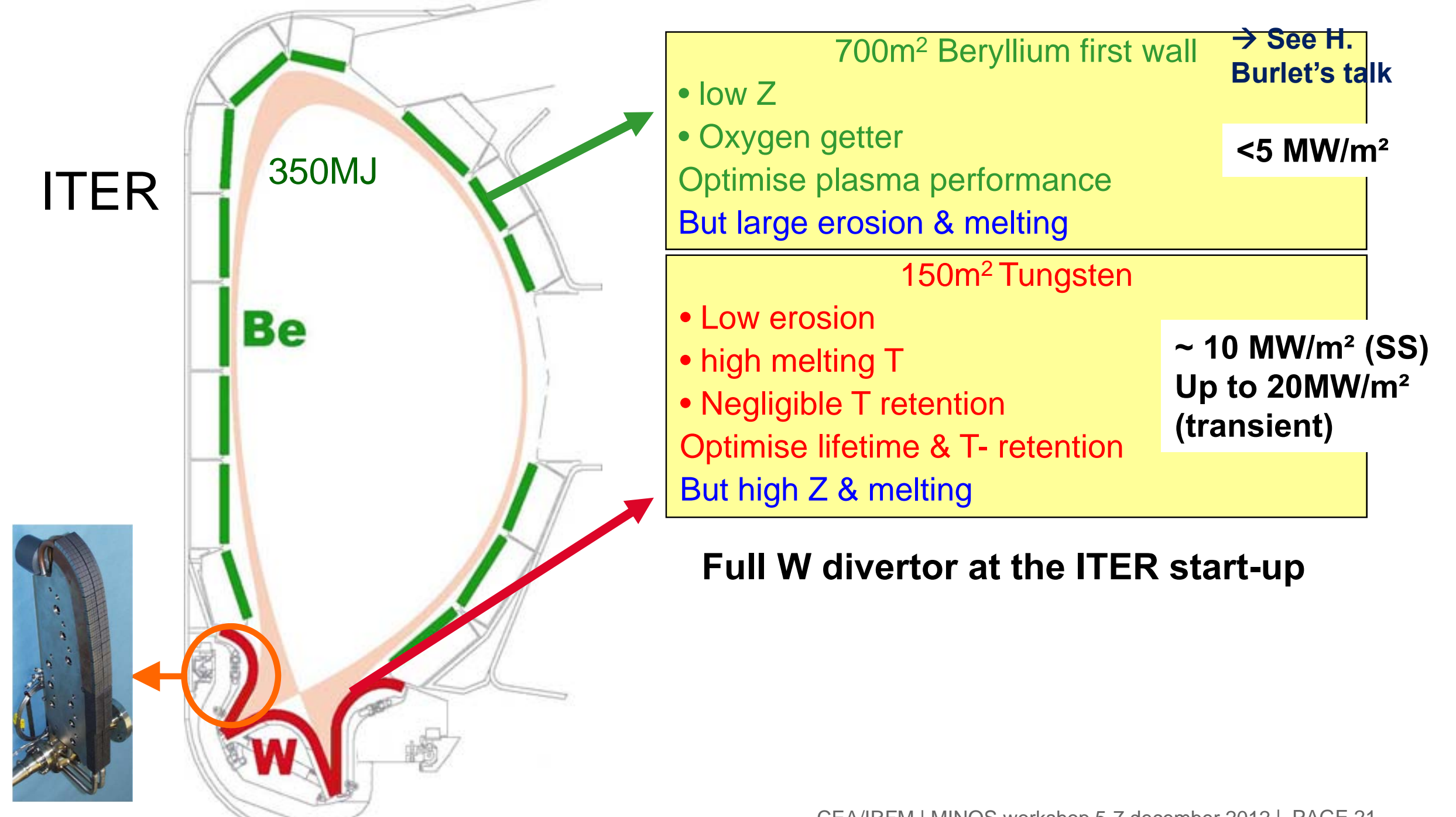




\section{CEA ITER DIVERTOR}

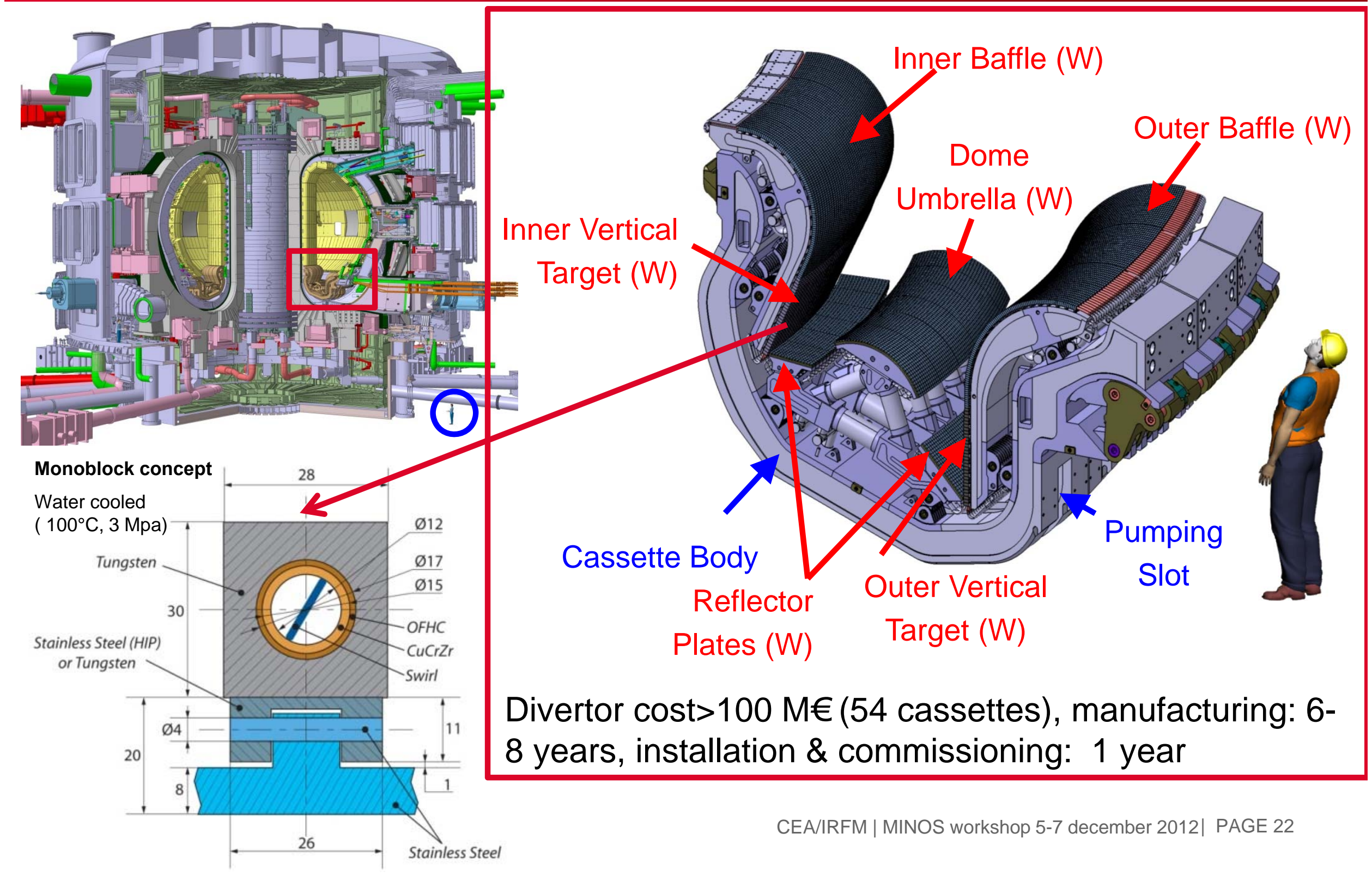




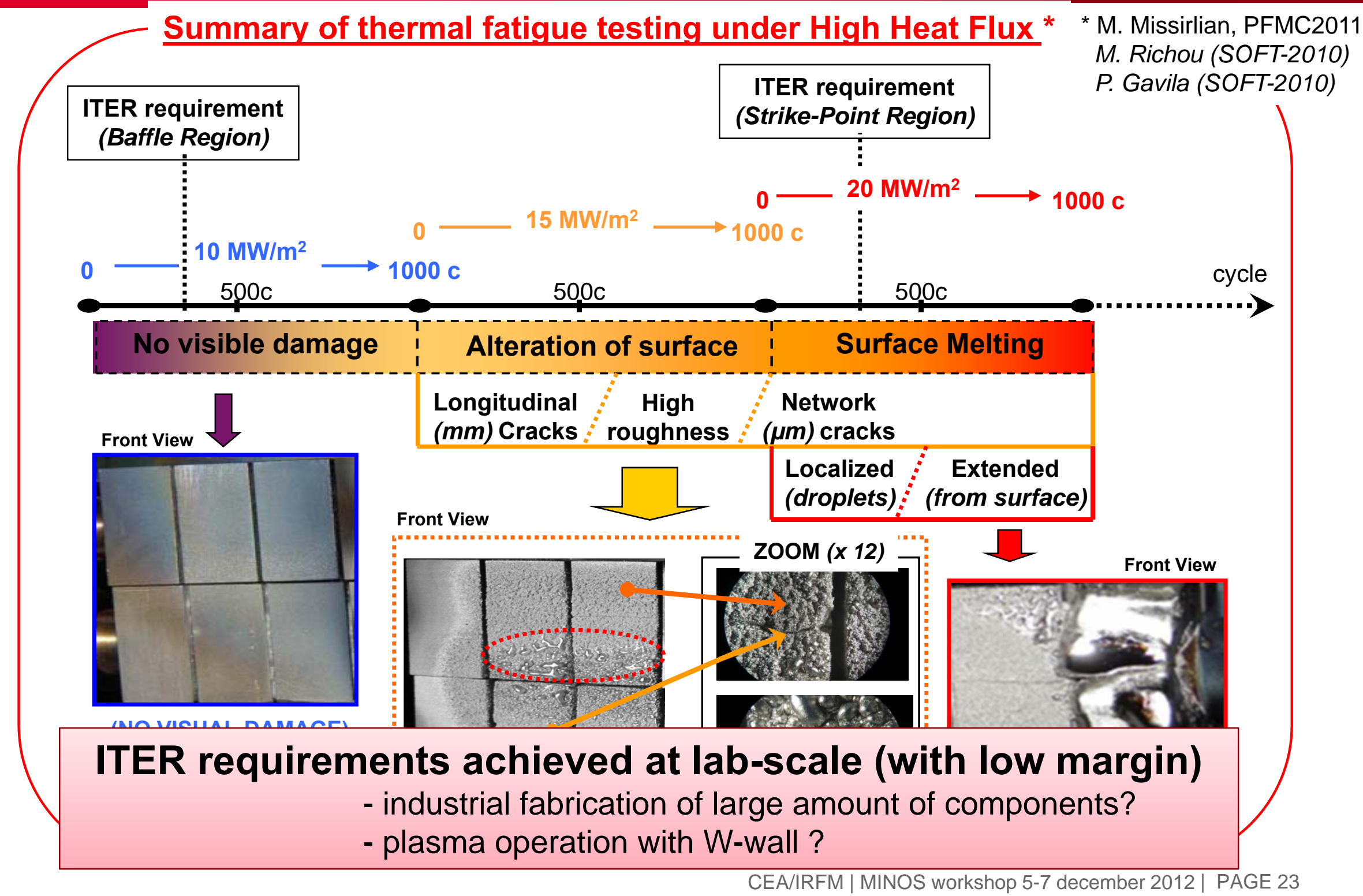


To prepare ITER operation, an Iter-like wall was installed in JET

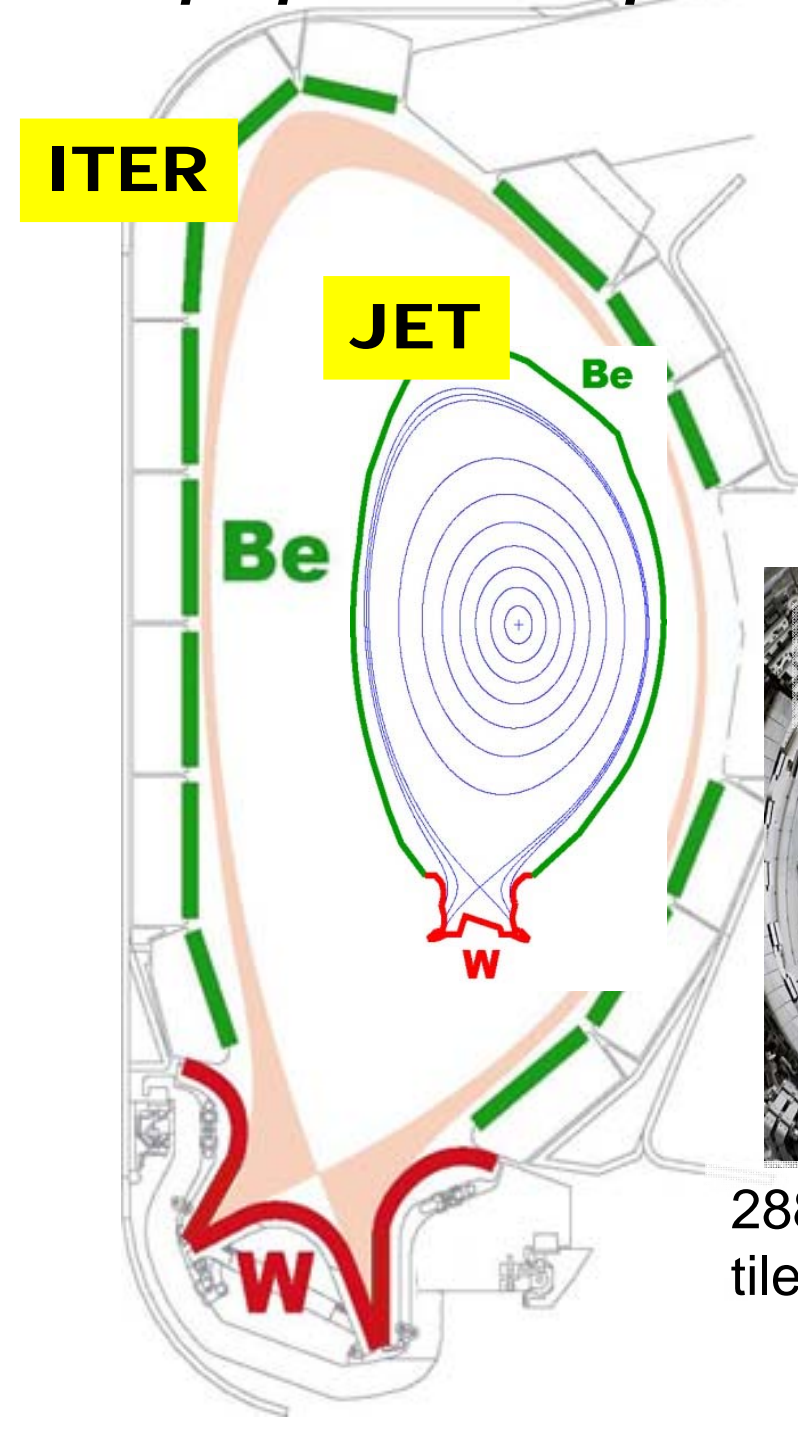

- Demonstrate sufficiently low fuel retention

L. Horton (SOFT-2012)

- Develop integrated ITER compatible scenarios for an allmetal machine

- Effect of transients (ELMs and disruptions) on ILW

- Develop control strategies for detecting and limiting damage...

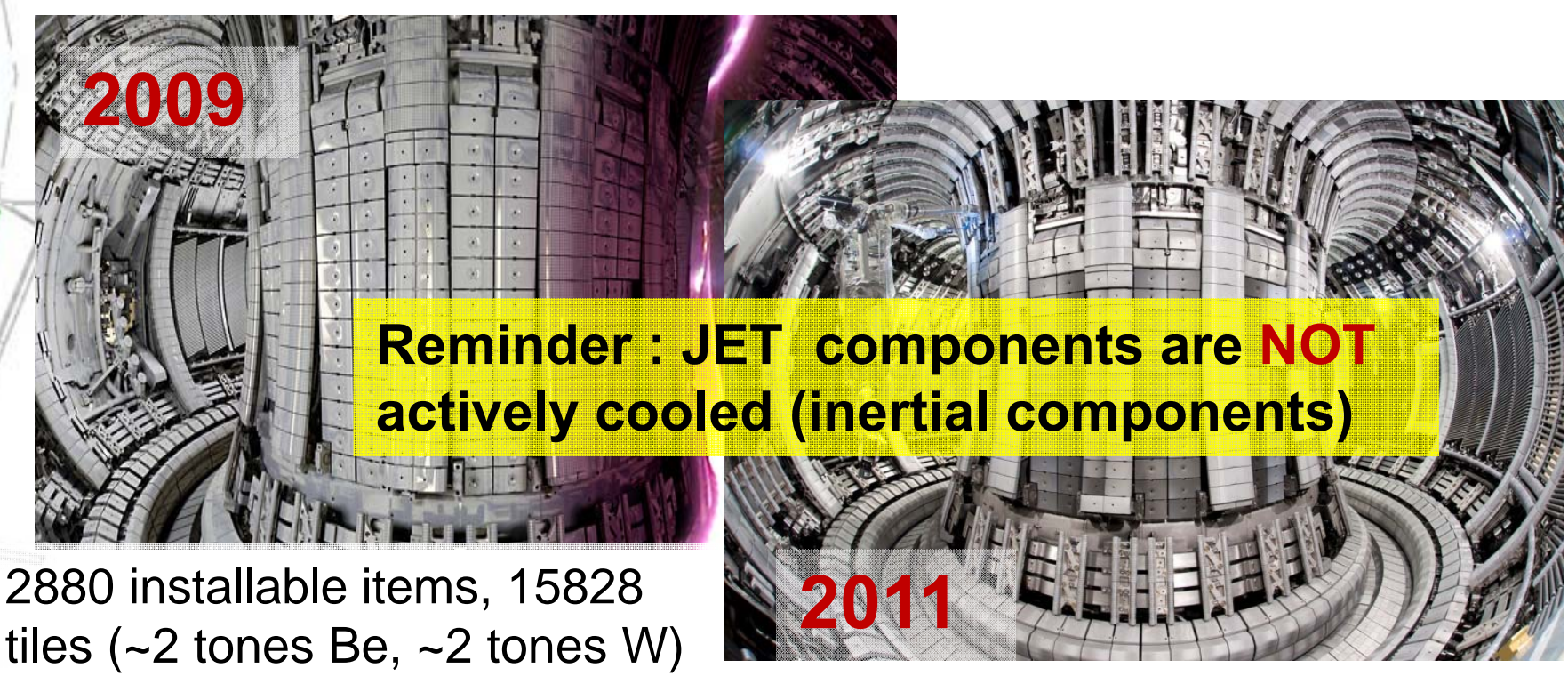




\section{JET ITER-LIKE WALL (ILW) EXPERIMENT}

E 2012 experimental campaign (main results)

- Qualification of new systems including protection wall system

- Beryllium and tungsten erosion are consistent with physical sputtering

- Measured fuel retention is more than an order of magnitude lower with the ILW, consistent with predictions made before the wall was installed

- The accumulation of tungsten into the core plasma limits the operating space with the ILW.

Confinement is typically $20 \%$ lower than with the carbon wall Understanding and improving these initial results is a priority for future experiments

- 2013 experimental campaign $\rightarrow$ Assessment of ITER operating scenarios 


\section{WEST : filling a gap in tungsten R\&D in EU}

Ehysics: operation of the tokamak with a tungsten wall (How to use a plasma in a tungsten environment)

$\rightarrow \sqrt{ }$ plasma, $x$ components
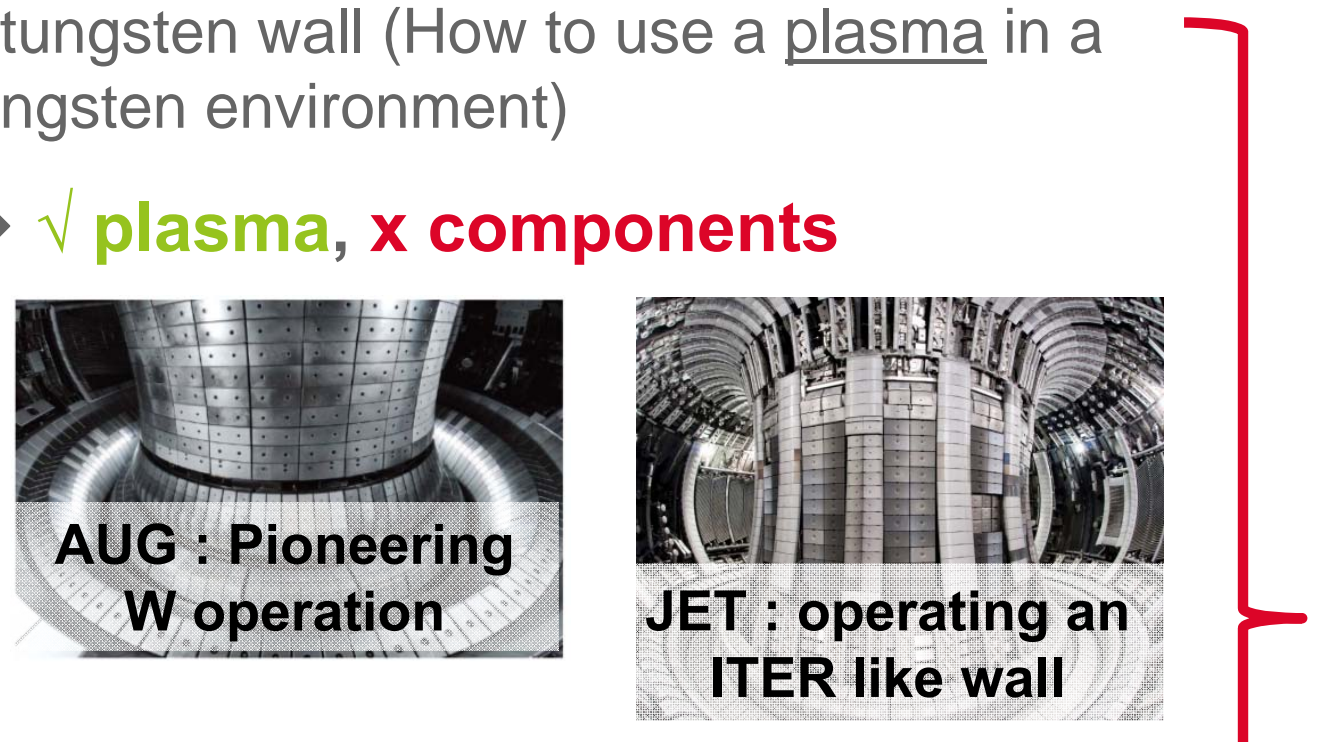

WEST : First integral test

Component technology at high flux + long pulse tokamak environment

$\rightarrow \quad \sqrt{\text { plasma, }} \sqrt{ }$ components

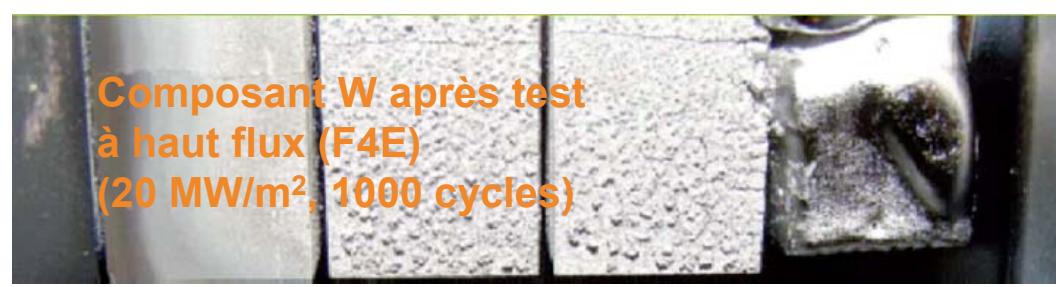


WEST (W Experiment in Steady state Tokamak) $\rightarrow$ implementation in Tore Supra of an divertor using the ITER technologie and a full $\mathbf{W}$ wall
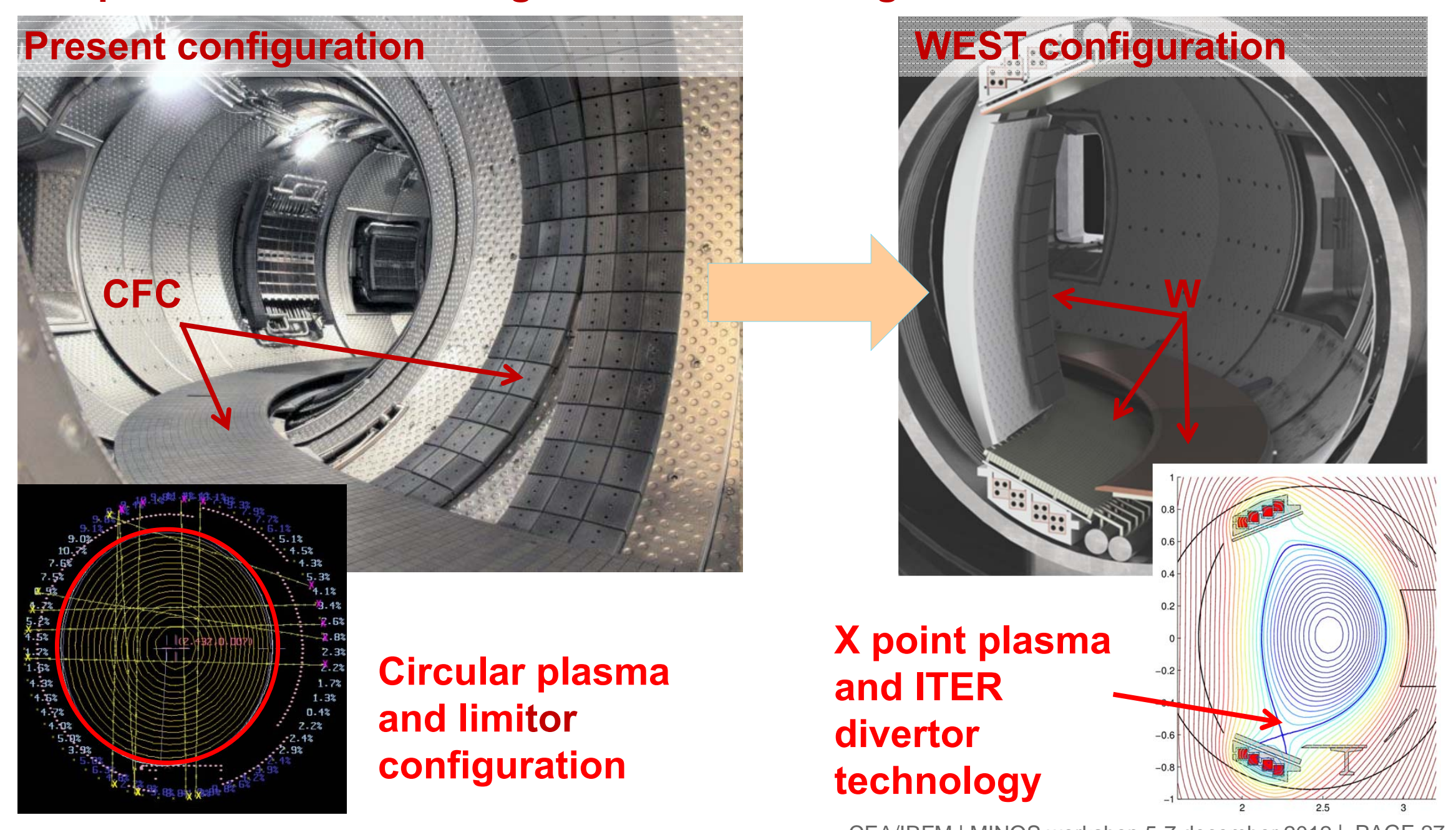

Circular plasma and limitor configuration

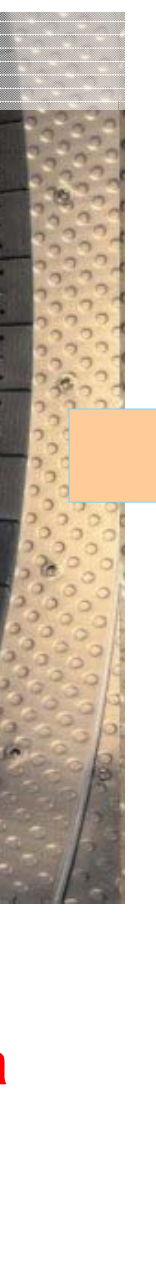




\section{Cea WEST : filling a gap in tungsten R\&D in EU}

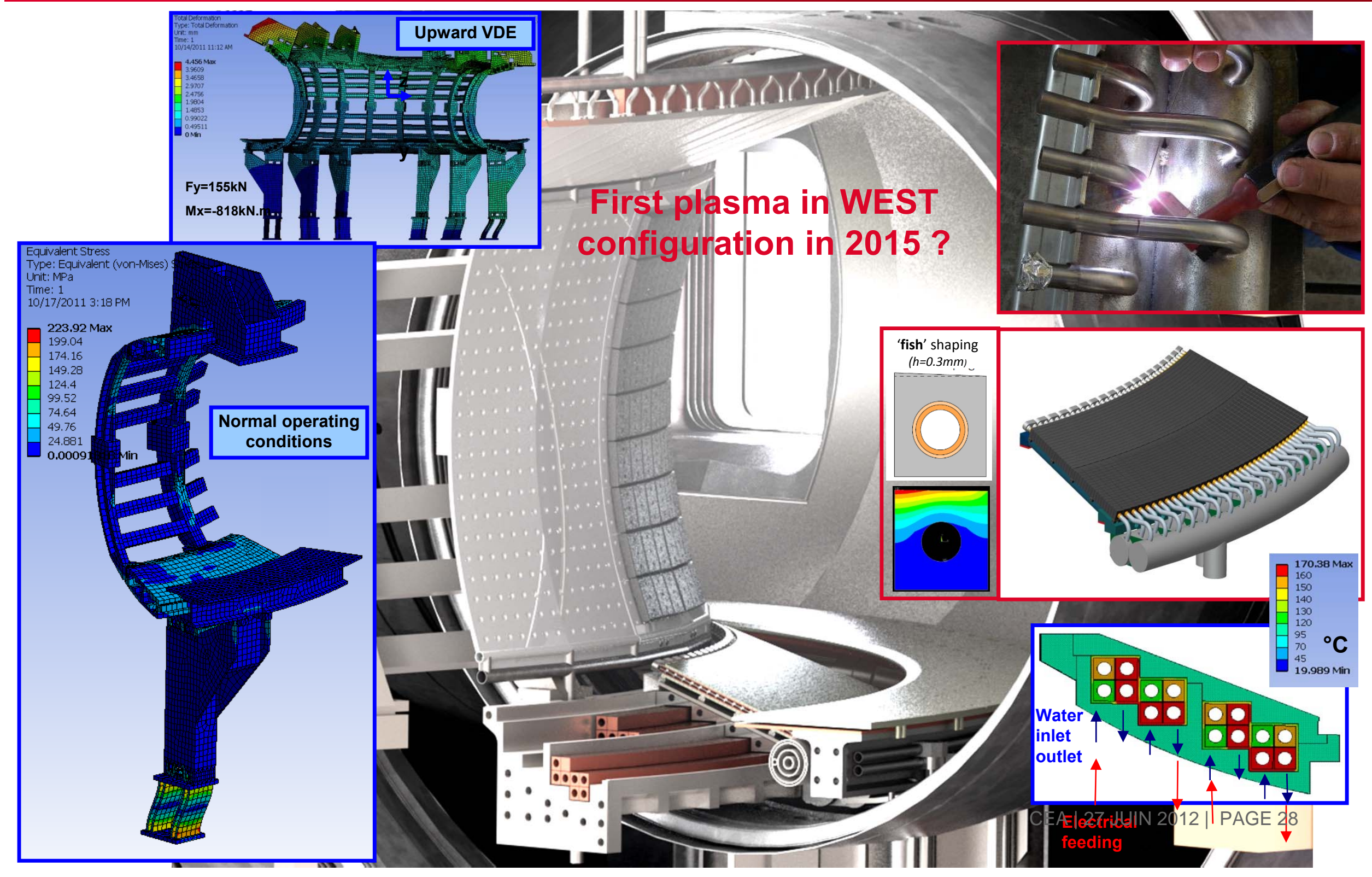


Fusion basics

I From present Plasma Facing Components (PFC)...

a ... to PFC for ITER

Toward the reactor 
Different approaches (ARIES studies in US, PPCS in EU, ...) and presently no consensus and no clear roadmap

- attractiveness (small is beautiful) $\rightarrow$ need large extrapolations both in physics \& technologies

- credibility $\rightarrow$ low extrapolations from ITER
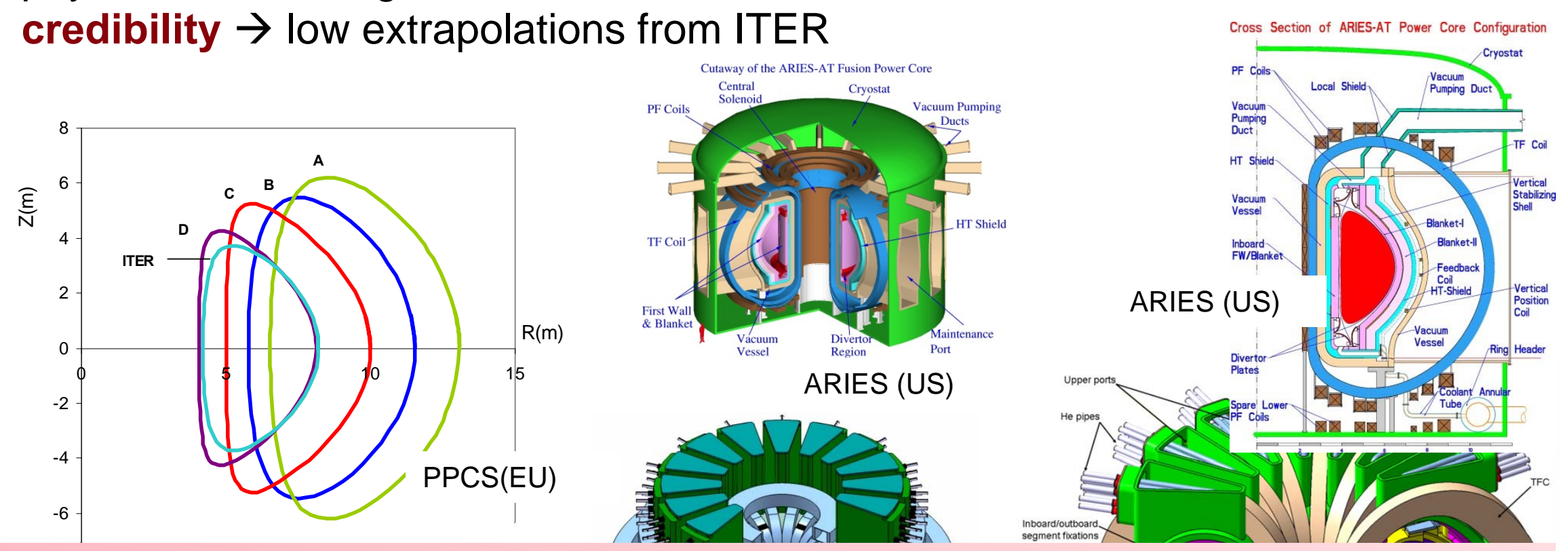

Example of 3 gaps to fill (among a lot) to reach the right level of credibility

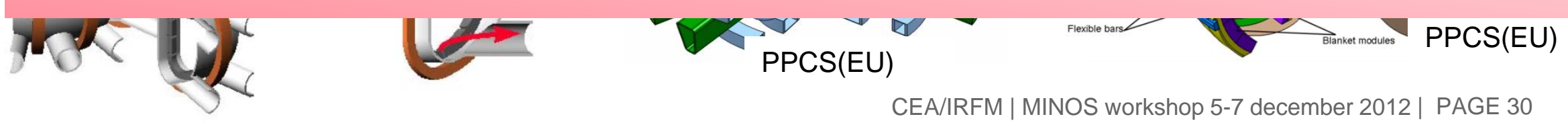




\section{NEUTRONS ARE A CONCERN FOR A REACTOR}

$\rightarrow$ Neutron fluence will increase

1. Yearly neutron damage in plasma-facing materials (dpa) :

0,5 (ITER) $\rightarrow$ 5-20 dpa (reactor)

$\rightarrow$ material properties will involve under $14 \mathrm{MeV}$ fusion neutron: thermal conductivity, swelling, traps for tritium both on structural material s and PFC

$\rightarrow$ see J. Henry's talk

Defect production in $\mathbf{W}$ and alpha-particle impingement will create a new situation (+ higher Twall) with possible new radiation induced microstructure in subsurface, which will determine the in-service behavior of $\mathrm{W}$ as armour material.

$\rightarrow$ New topic which need collaborative work between

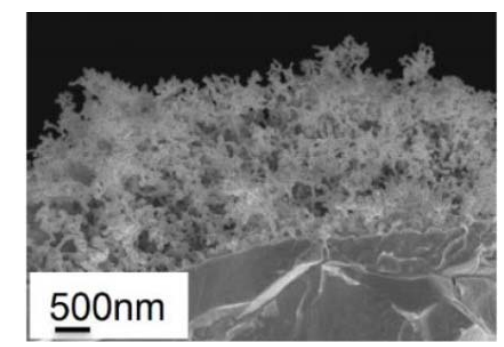
materials and plasma communities 


\section{CEA COOLING FOR ENERGY PRODUCTION}

$\rightarrow$ Neutron fluence will increase $\rightarrow$ new materials (R\&D on going)

$\rightarrow$ Higher coolant temperature for energy production

- ITER : water $\left(100^{\circ} \mathrm{C}, 3 \mathrm{MPa}\right) \rightarrow$ DEMO : water (in: $325^{\circ} \mathrm{C}$, out: $350^{\circ} \mathrm{C}$ )

Recent results of water-cooled divertor concepts based on ITER W monoblock and steels (Eurofer) for DEMO application, using nuclear design rules: HHF is limited to 10 $M W / m^{2}$

[A. LiPuma (CEA), SOFT2012]
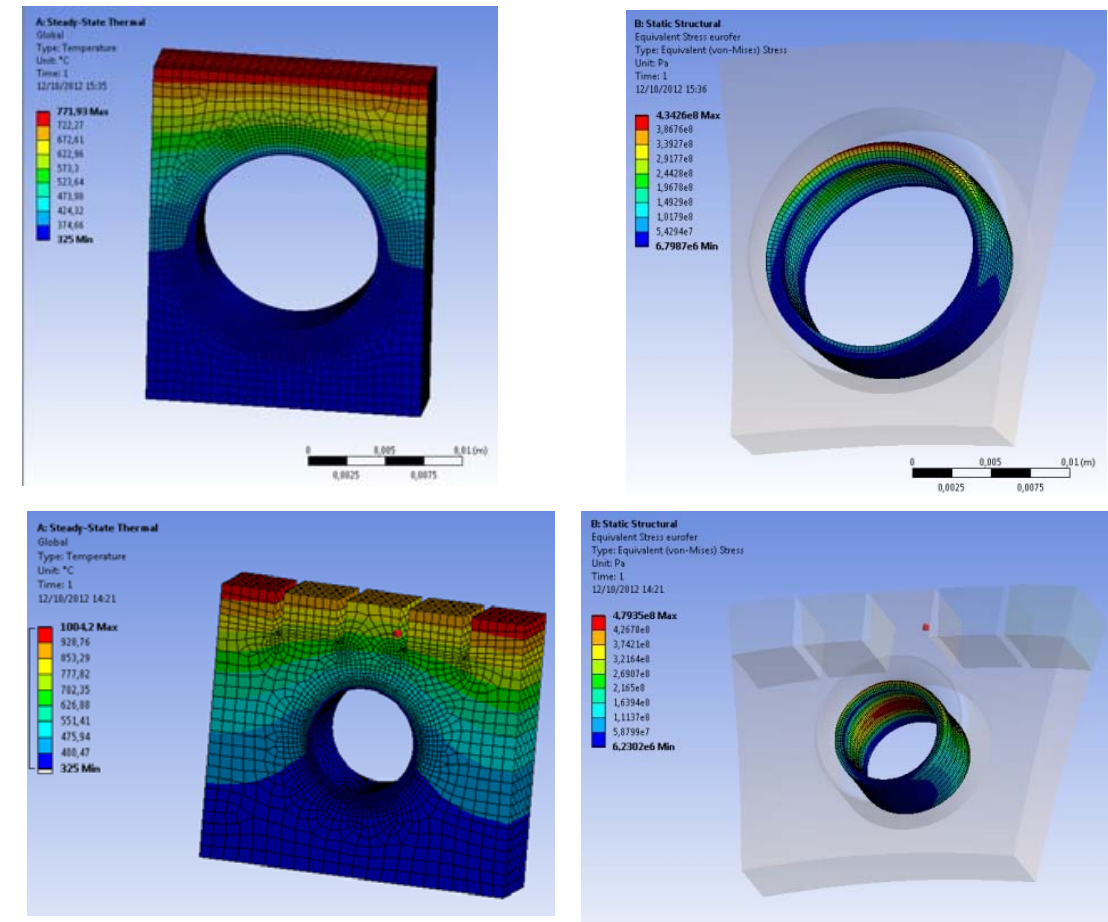

CEA/IRFM | MINOS workshop 5-7 december 2012 | PAGE 32 


\section{CEA COOLING FOR ENERGY PRODUCTION}

$\rightarrow$ Neutron fluence will increase $\rightarrow$ new materials (R\&D on going)

$\rightarrow$ Higher coolant temperature for energy production

I ITER : water $\left(100^{\circ} \mathrm{C}, 3 \mathrm{MPa}\right) \rightarrow$ DEMO : water (in: $325^{\circ} \mathrm{C}$, out: $350^{\circ} \mathrm{C}$ ) $\mathrm{He}\left(600^{\circ} \mathrm{C}, 10 \mathrm{MPa}\right)$

He cooled divertor, KIT concept

[A. Norajitra, JNM 2011]

\section{Tested à $10 \mathrm{MW} / \mathrm{m}^{2}$}

Main concerns: $\mathrm{W}$ as structural material, number of small components (350 000) and joining $\rightarrow$ reliability is questionable

$\rightarrow$ Design drives important R\&D on materials

- Functional gradient material [E. Autissier,CEA, SOFT2012]

- Powder Injection Molding [S. Antusch, KIT, FED 2011]

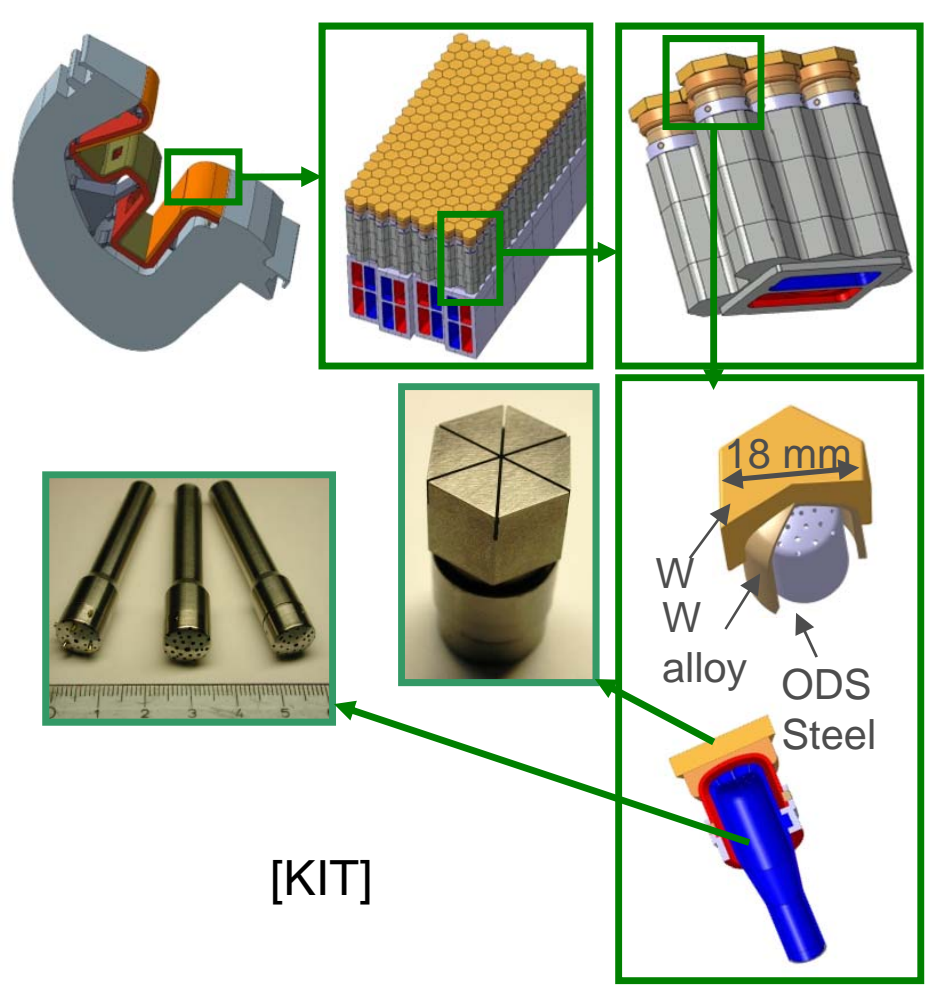




\section{POWER EXHAUST IS A CONCERN FOR DEMO}

$\rightarrow$ Heat flux on the divertor will increase

1. $\mathbf{P}_{\text {fusion }}: 500 \mathrm{MW}($ ITER) $\rightarrow 2500-5000 \mathrm{MW}$

$P_{\text {exhaust }}: 150 \mathrm{MW}($ ITER) $\rightarrow$ 500-1000 MW $\rightarrow \times 3$ to 7

Size (major radius) : $6.2 \mathrm{~m}$ (ITER) $\rightarrow 5.5 \mathrm{~m}$ (ARIES) to $10 \mathrm{~m}$ (Early DEMO)

$$
\rightarrow \mathrm{S}_{\text {divertor }} \times 2
$$

If $10 \mathrm{MW} / \mathrm{m}^{2}$ in steady state is a limit for the technology

1 ) New plasma configuration (ex: detached plasma, radiation mantle..)

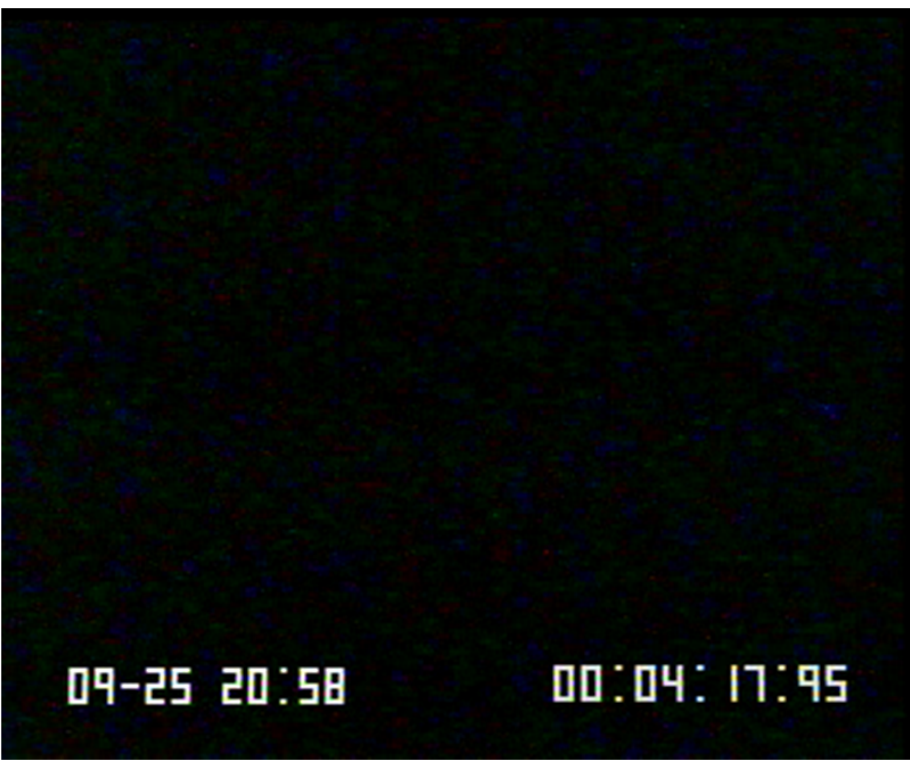

|Tore Supra team]

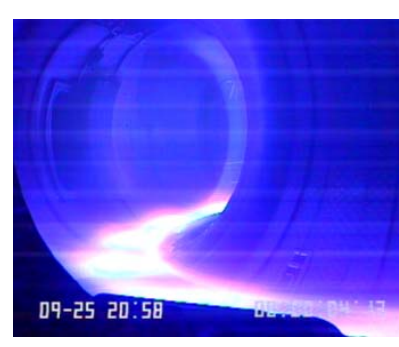

1 - plasma on the limiter

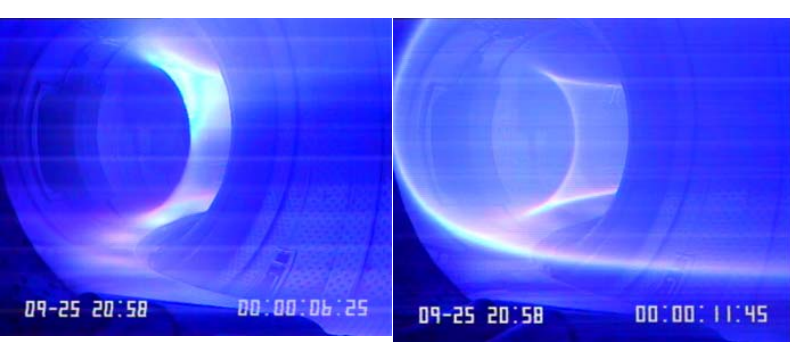

2 - start of 3 - detachment detachment (and ( $T_{\text {limiter }}$ decreases) control of the instabilities)

Radiation not only localized on the divertor (to be tested and validated on ITER) 


\section{POWER EXHAUST IS A CONCERN FOR DEMO}

$\rightarrow$ Heat flux on the divertor will increase

- $\mathbf{P}_{\text {fusion }}: 500 \mathrm{MW}($ ITER) $\rightarrow 2500-5000 \mathrm{MW}$

$P_{\text {exhaust }}: 150 \mathrm{MW}($ ITER) $\rightarrow$ 500-1000 MW $\rightarrow \times 3$ to 7

Size (major radius) : $6.2 \mathrm{~m}$ (ITER) $\rightarrow 5.5 \mathrm{~m}$ (ARIES) to $10 \mathrm{~m}$ (Early DEMO)

$$
\rightarrow \mathrm{S}_{\text {divertor }} \times 2
$$

If $10 \mathrm{MW} / \mathrm{m}^{2}$ in steady state is a limit for the technology

1 ) New plasma configuration (ex: detached plasma, radiation mantle..)

2 ) New divertor configuration to increase $S_{\text {divertor }}$

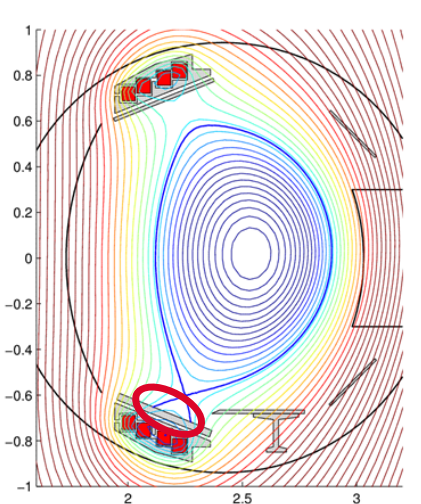

Conventional Divertor

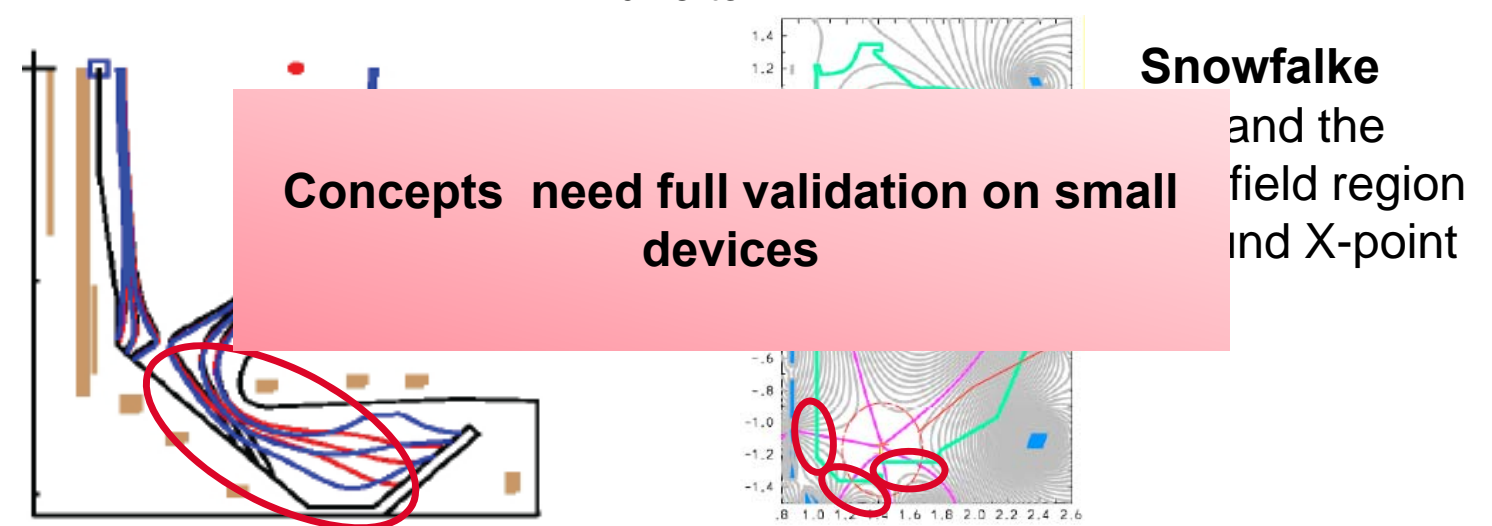

Super $\mathbf{X}$ : Extend leg on low field side 


\section{CONCLUSION}

- Plasma facing components are already a challenge but filling the gaps between present start of the art and ITER is on going

$\rightarrow$ to use $\mathrm{W}$ in fusion environment

$\rightarrow$ to mitigate risks in view of ITER operation (JET, WEST...)

Filling the gaps between ITER and a fusion reactor will require a large amount of R\&D

$\rightarrow$ assess materials (W, structural material) in the right physical chemistry range taken into account nuclear constraints (14 MeV neutrons, tritium)

$\rightarrow$ reach an equilibrium between PFC materials and plasma

- Plasma facing components are NOT only a material or a plasma physics or a technology issue but an integrated problem

$\rightarrow$ grand scientific challenge involving both material sciences, plasma physics and innovative design

$\rightarrow$ Good driver for material sciences !!! 


\section{Thank you for your attention}

